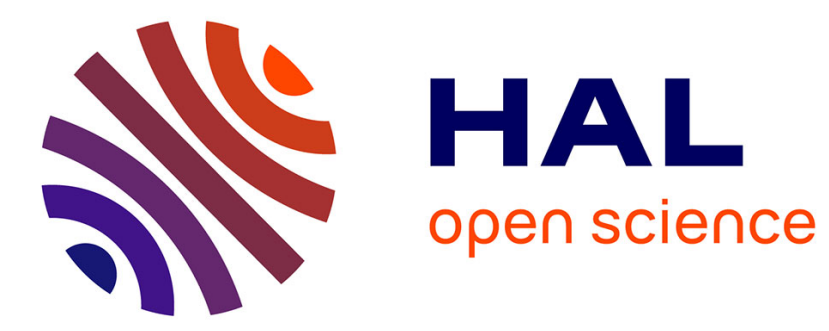

\title{
Exchange Rate Misalignments at World and European Levels: a FEER Approach
}

Se-Eun Jeong, Jacques Mazier, Jamel Saadaoui

\section{To cite this version:}

Se-Eun Jeong, Jacques Mazier, Jamel Saadaoui. Exchange Rate Misalignments at World and European Levels: a FEER Approach. Économie Internationale, 2010, 121 (Issue 1 2010), pp.25-58. halshs00435836v5

\section{HAL Id: halshs-00435836 \\ https://shs.hal.science/halshs-00435836v5}

Submitted on 25 Aug 2010

HAL is a multi-disciplinary open access archive for the deposit and dissemination of scientific research documents, whether they are published or not. The documents may come from teaching and research institutions in France or abroad, or from public or private research centers.
L'archive ouverte pluridisciplinaire HAL, est destinée au dépôt et à la diffusion de documents scientifiques de niveau recherche, publiés ou non, émanant des établissements d'enseignement et de recherche français ou étrangers, des laboratoires publics ou privés. 


\title{
CEPN

Document de travail du CEPN N²010-03

\section{Exchange Rate Misalignments at World and European Levels:}

\section{A FEER Approach}

Se-Eun Jeong ${ }^{*}$
Jacques Mazier

Jamel Saadaoui $^{\S}$

\begin{abstract}
Since the mid-1990s, we observe an increase of world current account imbalances. These imbalances have only been partially reduced since the burst of the crisis in 2007. They reflect, to some extent, exchange rate misalignments, an issue which has been frequently studied in the literature. However, these imbalances, which have reinforced in the 2000s, are also important inside the Euro area. This analysis cannot be reduced to simple estimates of euro misalignment at the world level because of the specific constraints that exist for each member of the Euro area. This article aims to examine to what extent the intra-European imbalances reflect exchange rate misalignments for each "national euro".
\end{abstract}

\section{Classification JEL: F31, F32}

Key words: Equilibrium Exchange Rate, Current Account Balance, Macroeconomic Balance

\footnotetext{
* Chungnam National University, College of Economics and Management, jseeun@cnu.ac.kr ${ }^{\ddagger}$ Paris North University, CEPN-CNRS, mazier@univ-paris13.fr

$\S$ Paris North University, CEPN-CNRS, jamelsaadaoui@gmail.com
}

We would like to thank Antonia López-Villavicencio for its econometric advices and language advices.
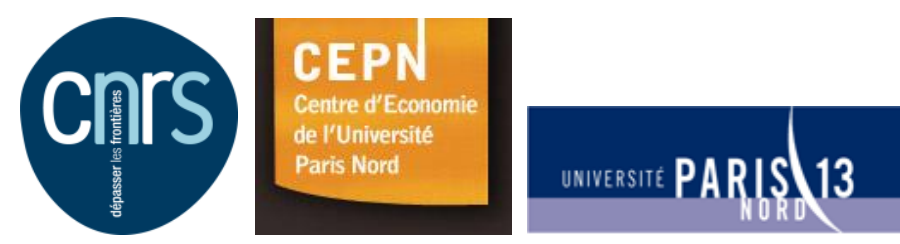


\section{Introduction}

Since the mid-1990s, world current account imbalances have increased significantly and have only been partially reduced since 2007 . These imbalances reflect inequalities in terms of growth, savings and investments and exchange rates misalignments. Exchange rates misalignments have been studied in details in the literature using two main approaches: the Behavioral Equilibrium Exchange Rate (BEER) and the Fundamental Equilibrium Exchange Rate (FEER). They generally concluded that the dollar was overvalued and that the euro undervalued during the first half of the 2000s. While these misalignments have been gradually reduced, the yuan remains undervalued since the second half of the 1990s.

However imbalances and misalignments also concern monetary unions like the Euro area, where intra-regional imbalances have increased since the early 2000s. Indeed, while the current account of the Euro area has remained close to equilibrium, the German surplus contrasts with the growing deficits of France, Italy and Spain.

The objective of this paper is to examine to what extent the intra-European imbalances reflect exchange rates misalignments specific to each Euro area members. Consequently, this analysis cannot be reduced to the simple estimate of euro misalignments but must also deal with misalignments of each "national euro".

For this purpose, a FEER approach is implemented. The FEER is defined as the level of exchange rate which allows the economy to reach the internal and external equilibrium at the same time (Williamson, 1983). The internal equilibrium is defined as the full utilization of productive resources of one country without generating inflation pressures. The external equilibrium corresponds to a sustainable current account.

In a first step, using a model of world trade, FEERs are estimated for the main currencies (the dollar, the euro, the yen, the yuan and the pound sterling). In a second step, FEERs can be estimated for each country of the Euro area, using simple national models and linking the estimation of national FEERs to the multinational model's results to get bilateral misalignments of each "national euro".

Our results confirm that exchange rate misalignments have been reduced since the mid-2000s at the world level, with the exception of the yuan which remains undervalued. Nevertheless, 
the misalignments seem to be more important for each individual Euro area member than for the whole Euro area. Especially, the undervalued "euro mark" contrasts with the overvalued "euro franc" and "euro peseta".

This paper is organized as follow. A second section summarizes the theoretical and methodological background. A third section presents the multinational model and the national models used to estimate the FEERs. A fourth section gives estimates of the external and internal equilibrium. A fifth section presents estimates of the FEER for the main currencies (the dollar, the euro, the yen, the yuan and the pound sterling) and for each "national euro". A last section concludes.

\section{Theoretical and methodological background}

By definition, exchange rate misalignment is defined as the gap, in percentage, between observed exchange rates and equilibrium exchange rates. Yet, various methodologies can be used to estimate equilibrium exchange rates.

\subsection{Equilibrium exchange rates methodologies}

The PPP (Purchasing Power Parity) is the oldest one and simplest methodology to estimate equilibrium exchange rates. In order to explain the movements of equilibrium exchange rates, this simple approach only relies on the relative prices. It ignores, however, other structural factors and seems too schematic, even when completed by a Balassa-Samuelson effect.

Beyond the PPP hypothesis, three main theories of equilibrium exchange rates can be distinguished: a) the Fundamental Equilibrium Exchange Rate (Williamson, 1983) and its recent developments (Cline, 2008), b) the Behavioural Equilibrium Exchange Rate which is an econometric approach (Clark and MacDonald, 1998) and c) the Natural Real Exchange Rate (NATREX) which tries to give a theoretical basis with a dynamic analysis (Stein and Allen, 1997).

The BEER approach explains the exchange rate dynamic with some main variables (usually the net foreign assets, the terms of trade, the productivity, the oil prices) which influence the real exchange rate at long term. 
A long term equation is first estimated by a co-integration method and then, using an error correction model, a short term equation is estimated. The exchange rate misalignments are simply measured by the gap between the observed exchange rate and its long run value. This econometric approach is rather easy to manage and gives useful results. But the theoretical basis can be regarded as underdeveloped and the recent improvements have been mainly econometric and statistics.

The NATREX develops a theoretical model with a distinction between short, medium and long term. The NATREX is supposed to assure the equilibrium of the current account independently of cyclical factors and of speculative capital flows. The internal equilibrium is supposed to be reached. But, beyond these theoretical foundations, the estimation of the NATREX relies on a reduced equation which is not clearly linked with the original model. Like in the case of the BEER, the approach is based on econometric tools with variables added at short term without clear justification and with a long term value which can hardly be regarded as an equilibrium one. (see e.g. Ahearne et al., 2007; Bouveret et al., 2006).

The FEER is defined as the exchange rate prevailing when the economy simultaneously reaches the external equilibrium (sustainable current account determined by structural parameters) and the internal equilibrium (full utilization of the productive potential). This approach is based on a structural model which mainly describes foreign trade relations and relates explicitly movements of exchange rates to internal and external imbalances. It has the advantage of focusing directly on structural parameters of each country. It allows for the estimation of equilibrium exchange rates of the different partners in a coherent manner by using a multinational trade model, which is rarely assured in other approaches. Its limited linkages with the inter-temporal optimizing literature are often criticized but the FEER does not pretend to describe the modality of the return to the equilibrium. It searches only, for each period, to estimate the real misalignment induced by the internal and external imbalances in terms of comparative statics.

Despite the fact that each approach has its advantages and its drawbacks, we prefer the FEER approach because it is more explicitly articulated with the structural characteristics of each country and it ensures greater consistency of estimates across countries. 


\subsection{The FEER approach and the SMIM}

Our objective is to assess the equilibrium exchange rates of countries of the euro area and compare them with the equilibrium exchange rate of the global euro. Our main argument is that the misalignment of the euro is not a pertinent indicator for each European country. For this, we need to conduct a two-step analysis in order to estimate the misalignments, first at the world level for the euro compared with the other main currencies (the dollar, the yuan, the yen and the pound sterling), second at the European level for each "national euro".

First, for the main currencies, the methodology used is a synthesis of previous works on the FEER (Borowski and Couharde, 2003, Jeong and Mazier, 2003) and of the Symmetric Matrix Inversion Method (SMIM) recently proposed by Cline (2008). A multinational model describing the foreign trade of the main countries and of the Rest of the World is used to calculate the main currencies' equilibrium exchange rates. It is well known that in a n-country model there are only $n-1$ independent bilateral exchange rates, because the first country's exchange rate (usually the dollar) is the numeraire against which the others are compared. Consequently, there is an overdetermination problem in the FEER approach, as there are more equations (current account targets) than unknowns (exchange rates).

In this paper, we use the $\mathrm{n}^{\text {th }}$ country as a residual in order to solve the overdetermination problem and to ensure the consistency of the world trade in volume and in value. Exports and imports of the residual country are calculated as residual of the world trade equilibrium in constant and current prices. But the equilibrium exchange rate of the residual currency, consistent with those of the other currencies, cannot allow the residual country to reach its equilibrium current account. In that respect the residual country is ignored in the estimation of the equilibrium exchange rates of the other currencies. In practice, in earlier works, it was generally the Rest of the World which was the residual country.

To avoid such an asymmetric approach and following the SMIM approach, the six countries (the United States, China, Japan, the United Kingdom, the Euro area and the Rest of the World) will be treated symmetrically by carrying out six sets of estimates with six multinational models where each country is treated successively as a residual. A simple average of the results could be obtained. However, there is a high degree of consistency in the alternative estimates of equilibrium exchange rates for any given country across the 5 solutions in which the current account target of the country in question is included (designated 
OCI for own country included). Conversely, there is sometimes a great difference between the average value and the value obtained in the resolution where the country or area target is not included (designated OCE for one country excluded). Consequently, the solution adopted in this paper will be to use as the estimate the average of equilibrium exchange rates obtained from all the solutions, except the one for which the country in question is regarded as a residual (OCI).

Secondly, for each country of the Euro area, an equilibrium exchange rate will be estimated using a simple national model of foreign trade. The equilibrium exchange rate will be defined, as previously, as the exchange rate compatible with the internal and external equilibrium of each country. It has been shown that, for a relatively small country like the European ones at the world scale, a national model gives results very close to the ones obtained with a multinational model where the studied country would be explicitly described (Jeong and Mazier, 2003).

This methodology improves previous works at several levels. Compared with approaches which ignore one area (the Rest of the World in practice), our model gives a symmetric treatment of all the countries, like Cline's SMIM, as each country is successively treated as residual. Compared with Williamson's earlier works using large econometric models, we construct simpler model to manage. However, the foreign trade model takes fully account of the interdependencies among main economies, including the one treated as a residual, which ensures consistency of worldwide results. Another advantage of our approach is the case of small countries which can be simply linked to the world model's results, as it will be explained more in detail. In this sense, our approach takes more consistently account of structural parameters of each economy and is more manageable than a model of thirty-five countries with a simple reduced equation between current account and real effective exchange rate for each country (Cline and Williamson, 2008). Moreover, our model incorporates the effects of the foreign debt service and of the oil prices on the current account but they are treated as exogenous.

Lastly, based on studies of the medium-term determinants of current accounts (Faruqee and Debelle, 1998, Chinn and Prasad, 2003), the equilibrium current account are determined by estimating structural determinants of current account (the demographic features, the developmental stage, the public deficit, the net foreign assets, etc...) relying on panel regression techniques. It avoids using an ad hoc approach which is often used, but seems less 
well founded. Sensitivity tests are conducted in order to assess the sensitivity of the results to adopted targets (current account target, internal equilibrium) and to values of parameters (price-elasticities).

\section{Macroeconomic modeling}

\subsection{The multinational model}

The model describes the trade structure of the main countries or areas, namely, the United States, Japan, China, the Euro area, the United Kingdom and the Rest of the World using standard foreign trade equations: export volume equation (1), import volume equation (2), export price equation (5) and import price equation (6). Each country is successively treated as a residual and in that case export and import volumes are determined as residual of the equations of world trade equilibrium in value (3) and in volume (4) while their export and import prices are determined in the same manner as for other trading partners. We notice that this multinational specification gives a full account of interdependent effects in volume and prices of exports and imports of all countries. We incorporate a consumer prices equation (7) to take into account the feedback effect between the consumer prices and the import prices. The real effective exchange rate is defined relatively to the consumption prices. Finally, the current account is defined as in equation (9). For the residual country, its current account can be calculated (equation (9.a)) but is not taken in account.

With usual notations, the model is written as:

\section{Foreign trade volume equations}

Export volume equation

$$
\begin{aligned}
& X_{i}=X_{0 i} D M_{i}^{\eta x i} C O M P X^{\varepsilon x i} \\
& D M_{i}=\prod_{j \neq i} M_{j}^{\alpha i j} \\
& \operatorname{COMPX}_{i}=\left(\frac{P M X_{i}}{P X_{i}}\right)
\end{aligned}
$$

Import volume equation

$$
M_{i}=M_{0 i} D I_{i}^{\eta m i}\left(\frac{P D_{i}}{P M_{i}}\right)^{\varepsilon m i}
$$

With $\mathrm{i}=1 \sim 5$ among Japan, China, U.S., Euro area, U. K., Rest of the World $\}=\{$ all the countries except the residual one\} 
World trade equilibrium in value and in volume

Equilibrium in value

$\frac{\sum_{i} P X_{i} X_{i}}{E_{i}}=\frac{\sum_{i} P M_{i} M_{i}}{E_{i}}$

Equilibrium in volume

$\sum_{i} X_{i}=\sum_{i} M_{i}$

With $\mathrm{i}=1 \sim 6$

\section{Price equations}

Export price equation

$$
\begin{aligned}
& P X_{i}=P M X_{i}^{\alpha x i} P_{i}^{1-\alpha x i} \\
& P M X_{i}=\prod_{j \neq i}\left(\frac{E_{i} P X_{j}}{E_{j}}\right)^{\lambda i j}
\end{aligned}
$$

Import price equation

$$
\begin{aligned}
& P M_{i}=P M_{i}^{\alpha m i} P D_{i}^{1-\alpha m i} \\
& P M_{i}=\prod_{j \neq i}\left(\frac{E_{i} P X_{j}}{E_{j}}\right)^{\mu i j}
\end{aligned}
$$

Consumer price equation

$$
P D_{i}=P M_{i}^{a i} P_{i}^{1-a i}
$$

Real effective exchange rates

$$
R_{i}=\prod_{j \neq i}\left[\left(\frac{P D_{j}}{E_{j}}\right)^{v i j} /\left(\frac{P D_{i}}{E_{i}}\right)\right]
$$

With $\mathrm{i}=1 \sim 6$

\section{Current account}

Current account

$$
\begin{aligned}
& B_{i}=P X_{i} X_{i}-P M_{i} M_{i}-E_{i} P_{p e t} M_{\text {peti }}-i_{i} E_{i} F_{i} \\
& B_{\text {res }}=-\sum_{i=1}^{5} B_{i}
\end{aligned}
$$

With $\mathrm{i}=1 \sim 5$ \{among Japan, China, U.S., Euro area, U. K., Rest of the World $\}=\{$ all the countries except the residual one $\}$

The multinational model variables are defined as follow: $X$, non-oil exports in volume; $D M$, world demand in volume; DI, internal demand in volume; COMPX, export prices competitiveness; $P X$, export prices; $P M X$, competitor export prices; $M$, non-oil imports in volume; $P M$, import prices; $P M M$, world import prices; $P D$, consumer prices; $P$, production 
prices; $E$, nominal bilateral exchange rates vis-à-vis the dollar; $R$, real effective exchange rates; $B$, current account; $i$, interest rates for external debt; $F$, net external debt; $P_{\text {pet }}$, oil price; $M_{\text {pet }}$, net oil import.

We notice that in the model the dollar plays the role of numeraire $\left(E_{3}=1\right)$ and the bilateral exchange rates of other currencies against the dollar are written as 1 dollar $=E_{1}$ yens $=E_{2}$ yuans $=\mathrm{E}_{4}$ euros $=\mathrm{E}_{5}$ pounds $=\mathrm{E}_{6}$ monetary unities of the Rest of the World.

In this framework, FEERs are defined as the real effective exchange rates compatible with the simultaneous realization of the internal and external equilibrium at medium term of each trading partner. The internal equilibrium means that actual output follows the potential production and the external equilibrium means that actual current account corresponds to the sustainable current account at medium term.

The model is written in logarithmic differential compared with the equilibrium, which directly calculates the extent of the misalignment. Variables in lower case correspond to the $\log$ differences of these variables, thus $e=d E / E=\left(E-E^{e}\right) / E^{e}$ for the bilateral exchange rate and $x=d X / X=\left(X-X^{e}\right) / X^{e}$ for other variables, except for current account $b=(B / P Y)-(B / P Y)^{e}$ where $b$ represents the difference between the observed current account and the equilibrium current account as a percentage of GDP. The values of bilateral exchange rate misalignments (e) are given by solving the model in logarithmic differential (appendix 1).

On the whole, each multinational model comprises 35 endogenous variables $(x, m, p x, p m, p d$ for the six countries or areas and the five bilateral exchange rates $e$ ) for 35 equations $(x, m, b$ for the five countries other than the residual one, $p x, p m, p d$ for the six countries and the two world trade equilibrium equations). The real effective exchange rates are calculated ex post using bilateral exchange rates and consumer prices.

The production prices $p$ are supposed to be at equilibrium, which means that we do not include a price-wage loop in our model. The two exogenous variables are the internal and the external equilibrium gap ( $d i$ and $b$, respectively).

In logarithmic differential form, the degree by which the economy deviates from its internal and external equilibrium determines the degree of misalignments of its currency. On the one hand, the degree of deviation of internal demand is measured by $d i=\left(D I-D I^{e}\right) / D I^{e}$ where 
$D I^{e}$ is the equilibrium internal demand. This equilibrium internal demand is linked to the potential production. On the other hand, the gap between actual current account and equilibrium one, as a percentage of GDP, is given by $b=(B / P Y)-(B / P Y)^{e}$. This variable, which quantifies the deviation from the external equilibrium, is central in determining exchange rate misalignments.

As mentioned before, each country is treated successively as residual, which gives six multinational models. The six countries are treated symmetrically, including the Rest of the World, and six sets of estimates are done successively with each multinational model. In each case it permits to calculate an "equilibrium exchange rate" of the residual currency $\left(e_{r e s}\right)$ coherent with the equilibrium exchange rates of the five other countries, but not with its current account target. A simple average of the results could be obtained. But it is preferable to use as an estimate of the equilibrium exchange rates the average obtained for all the solutions, except the one for which the country in question is regarded as a residual (OCI).

\subsection{The national model}

For each country of the Euro area, it is possible to estimate a specific equilibrium exchange rate which is different from the euro's one. Although the bilateral exchange rate of the euro against the dollar is the same for all the Euro area's members, the nominal and real effective exchange rates of each European country are different, due to important differences in their foreign trade structures. Furthermore, in spite of progress in European economic and financial integration, European countries are still marked by large differences at the structural and

institutional levels. This justifies the estimation of equilibrium exchange rates for each Euro area's members.

This can be done using a foreign trade model for each European country in which the world demand and world trade prices are exogenous. As explained above, it is not necessary for a relatively small country like the European ones at the world scale, to use a multinational model to estimate equilibrium exchange rates. The following equations specify the trade volume and price equations for a small country facing world economy. The equation (14) describes the formation of current account.

$$
X_{i}=X_{0 i} D_{i}^{*} \eta x i\left(\frac{E_{i} P_{i}^{*}}{P X_{i}}\right)^{\varepsilon x i}=X_{0 i} D_{i}^{*} \eta x i R_{i}^{(1-\alpha x i) \varepsilon x i}
$$




$$
\begin{aligned}
& M_{i}=M_{0 i} D I_{i}^{\eta m i}\left(\frac{P_{i}}{P M_{i}}\right)^{\varepsilon m i}=M_{0 i} D I^{\eta m i} R_{i}^{-\alpha m i \varepsilon m i} \\
& P X_{i}=\left(E_{i} P_{i}^{*}\right)^{\alpha x i} P_{i}^{1-\alpha x i}=R_{i}^{\alpha x i} P_{i} \\
& P M_{i}=\left(E_{i} P_{i}^{*}\right)^{\alpha m i} P_{i}^{1-\alpha m i}=R_{i}^{\alpha m i} P_{i} \\
& B_{i}=P X_{i} X_{i}-P M_{i} M_{i}-E_{i} P_{p e t} M_{p e t i}-i_{i} E_{i} F_{i} \\
& R_{i}=\left(\frac{E_{i} P_{i}^{*}}{P_{i}}\right) \\
& P_{i}^{*}=P X_{i}^{*}=\prod_{j \neq i}\left(\frac{P X_{j}}{E_{j}}\right)^{\lambda i j} \cong P M_{i}^{*}=\prod_{j \neq i}\left(\frac{P X_{j}}{E_{j}}\right)^{\mu i j}
\end{aligned}
$$

With $\mathrm{i}=1 \sim 9$ \{France, Germany, Italy, Spain, Austria, Finland, Ireland, Netherlands, Portugal $\}$ and $\mathrm{j}=1 \sim 6$ \{Japan, China, U.S., Euro area - country i, U. K., Rest of the World $\}$

The national model variables are defined as follow: $X$, non-oil exports in volume; $D^{*}$, world demand in volume; $P^{*}$, world prices; $P X$, export prices; $M$, non-oil imports in volume; $D I$, internal demand in volume; $P M$, import prices; $P$, production prices; $E$, bilateral exchange rate against the dollar; $R$, real effective exchange rates; $B$, current balance; $i$, interest rates for external debt; $F$, net external debt; $P_{p e t}$, oil price; $M_{\text {pet }}$, net oil import.

Solving this simplified model in logarithmic differential (appendix 2) form gives $r$, misalignment of "national euro" in real effective terms $\left(r=d \log R=d R / R=\left(R-R^{e}\right) / R^{e}\right)$ :

$$
r_{i}=\left[\frac{\left(\left(b_{i} / \mu_{i} T_{i}\left(1-\sigma_{p e t x i}-\sigma_{x i}\right)\right)+\eta m_{i} d i_{i}-\eta x_{i} d_{i}^{*}\right)}{\left(\left(1-\alpha x_{i}\right) \varepsilon x_{i}+\varepsilon m_{i} \alpha m_{i}+\alpha x_{i}-\alpha m_{i}\right)}\right]
$$

Where $\sigma p e t x=E P_{p e t} M_{p e t} / P X X$, ratio of net oil imports on non-oil exports and $\sigma x=i E F / P X X$, ratio of foreign debt service on non-oil exports.

The FEER approach focuses on real effective exchange rates. However, the nominal bilateral 
exchange rate against the dollar of each "national-euro" can be more intelligible. By using the equation (15), we can find out $e$, the degree of misalignment in bilateral nominal terms; the partner countries' misalignments are given by the previous multinational model:

$e_{i}=r_{i}-\sum_{j \neq i} \lambda_{i j}\left(p x_{j}-e_{j}\right)$

We can also compute the effective exchange rate misalignments based on consumer prices:

$$
r c_{i}=\left(1-\alpha m_{i} \mu_{i}\right) r_{i}+\sum_{j \neq i} y_{i j}\left(p d_{j}-e_{j}\right)-\sum_{j \neq i} \lambda_{i j}\left(p x_{j}-e_{j}\right)
$$

\subsection{Foreign trade elasticities}

Without doing original econometric work, trade equations are taken from existing estimations realized with specifications close to the standard model presented before. We use especially long-term elasticities. Considering the uncertainties surrounding the estimations, sensibility tests to elasticities modifications are provided in annex.

The elasticities of the MIMOSA model for Japan, the United States and the United Kingdom (close to those of Wren-Lewis), those of Dées for China and those of Hervé for the Euro area are taken for our simulation. The price elasticities are rather in accordance with the generally admitted hierarchical position of countries in the world trade. The relatively weak value for China could be surprising, but might be explained by the particular nature of the Chinese trade. The trade model of China was estimated for the period 1985-1998 and for the first half of the 1980s the role of exchange rates in exports and imports is considered as little significant. Notice also that Japanese and American exporters turn out to be largely price maker. The price elasticities are weaker in the OECD (2005) publication as they concern the total trade of good and services. For the Rest of the World ad hoc values have been used, but are close to estimations of elasticities made using data from CHELEM and OECD. (The elasticities of the trading partners of the multinational model are presented in appendix 3)

For European countries, the selected elasticities are those of the MIMOSA model for France, Germany and Italy. For other European countries, the elasticities are derived from a previous contribution on interdependencies and adjustments in the European Union (Mazier and Saglio, 2008). These elasticities are presented in appendix 4. 


\section{External and internal equilibrium at medium term}

\subsection{Estimation of equilibrium current account}

As the current account equals the difference between domestic saving and investment (i.e. the saving-investment balance), the current account developments are examined from the perspective of the medium and long run determinants of saving and investment behaviors (Faruqee and Debelle, 1998, Chinn and Prasad, 2003). According to these authors, the main determinants of the current account at medium term are: the demographic characteristics, such as, the dependency ratios of dependent populations relative to the working age population, which is expected to exert a negative influence, with a higher dependency ratio leading to more spending; the net foreign asset, which is expected to have a positive effect, due to the capital income resulting from it; the government budget balance, with a public deficit having a negative effect on the current account, but this effect may be regarded as a simple accounting one which should not to be introduced ${ }^{1}$. Finally, we introduce a short-term effect, the output gap, since a higher utilization of production capacity leads to a deterioration of the current account. Yet, this last variable will be eliminated in the simulation of the equilibrium current account.

The equations of current account are estimated with panel data for 1980-2003 period and for two groups of countries. In a medium term perspective, we use non-overlapping four years average of annual data (Lee et al., 2008).

$$
C A_{i t}=\alpha_{i}+\alpha_{t}+\beta_{0}+\beta_{1} I S N F A_{i t}+\beta_{2} C D R_{i t}+\beta_{3} O D R_{i t}+\beta_{4} O G_{i t}+\varepsilon_{i t}
$$

The variables of equation (20) are defined as follows: $C A$, current account as $\%$ of GDP; ISNFA, initial stock of net foreign assets at the beginning of each period of 4 years as $\%$ of GDP; $C D R$, child dependency ratio, population under the age of 15 years as \% of population aged 15 to $64 ; O D R$, old dependency ratio, population over the age of 65 years as $\%$ of population aged 15 to $64 ; O G$, output gap in $\%$ of the potential production. The sources

\footnotetext{
${ }^{1}$ There are other variables, such as the openness ratio, which plays negatively, a higher openness meaning a greater possibility of assuring the debt service in the future, or the relative real GDP per capita, which exerts a non linear influence according to stages of development. We tried these variables, but results were not significant enough. Moreover, relative GDP per capita is evaluated non stationary by most of tests.
} 
of the different variables are presented in appendix 5. One group is composed of 19 industrial countries (Australia, Austria, Canada, Denmark, Finland, France, Germany, Ireland, Italy, Japan, Netherlands, New Zealand, Norway, Portugal, South Korea, Spain, Sweden, the United Kingdom and the United States) and will be used for determining the current account targets of the United States, Japan, the Euro area, the Euro area's members and the United Kingdom. The other group, composed of 20 emerging economies (Argentina, Brazil, Chile, China, Colombia, Ecuador, Egypt, India, Indonesia, Malaysia, Mexico, Morocco, Pakistan, Peru, Philippines, South Africa, Sri Lanka, Thailand, Tunisia and Turkey), will be used for determining the current account target of China.

The results of unit root tests are presented in appendix 6. As it can be seen, we reject the null hypothesis of non-stationarity in all the series.

For industrialized countries, the estimated coefficients of equation (20) are on the whole significant with the predicted signs (Table 1) in different specifications. The dependency ratios are not highly significant, although they are the best theoretically justified variables. Output gap turns out to have negative effects on current account. Country effects raise the determination ratio. On the whole the cross section specification with country fixed effects seems the most relevant and is adopted in order to calculate the equilibrium current account.

Table 1. Determinants of the current account for industrialized countries

\begin{tabular}{cccc}
\hline & OLS Pooled & Individual Fixed Effects & Temporal Fixed Effects \\
\hline \multirow{2}{*}{ Constant } & $6.69^{* *}$ & $11.27^{* * *}$ & 0.69 \\
& $(2.14)$ & $(3.29)$ & $(0.29)$ \\
ISNFA & $0.06^{* * *}$ & $0.02^{* * *}$ & $0.07^{* * *}$ \\
& $(10.87)$ & $(2.22)$ & $(8.51)$ \\
CDR & $-0.16^{* *}$ & $-0.26^{* * *}$ & 0.00 \\
& $(-2.23)$ & $(-4.18)$ & $(0.02)$ \\
ODR & -0.09 & $-0.19^{* *}$ & -0.03 \\
\multirow{2}{*}{$\boldsymbol{O G}$} & $(-1.32)$ & $(-2.28)$ & $(-0.51)$ \\
& $-0.31^{* * *}$ & $-0.47^{* * *}$ & $-0.51^{* * *}$ \\
Adjusted $\boldsymbol{R}^{2}$ & $(-2.82)$ & $(-5.77)$ & $(-4.09)$ \\
\hline
\end{tabular}

(Source: authors' estimates)

$(()=\mathrm{T}$ statistics; $* * *=$ significant at $1 \%, * *=$ significant at $5 \%, *=$ significant at $10 \%)$

(Coefficients robust to heteroskedasticity) 
Results for emerging countries are less conclusive than those for industrial countries, as in the case of other empirical studies (Chinn and Prasad, 2003). As previously, the coefficients are on the whole significant with predicted signs in the different specifications, with some exceptions (Table 2). Comparing cross section specification with the fixed effects and the pooled OLS, the former has a higher determination ratio, but the net foreign asset has a negative sign and the old dependency ratio a positive one, which can hardly be explained. A possible explaination is that the NFA are more dispersed in the case of emerging countries and they might capture individual fixe effects. Consequently, panel OLS specification is adopted to estimate equilibrium current accounts for emerging countries.

Table 2. Determinants of current account for developing countries

\begin{tabular}{|c|c|c|c|}
\hline & OLS Pooled & Individual Fixed Effects & Temporal Fixed Effects \\
\hline Constant & $\begin{array}{c}6.46^{* * * *} \\
(3.50)\end{array}$ & $\begin{array}{l}-4.22 \\
(-1.13)\end{array}$ & $\begin{array}{c}-0.28 \\
(-0.12)\end{array}$ \\
\hline ISNFA & $\begin{array}{c}0.02 * * * * \\
(6.46)\end{array}$ & $\begin{array}{l}-0.01 * \\
(-1.66)\end{array}$ & $\begin{array}{c}0.04 * * * \\
(4.22)\end{array}$ \\
\hline$C D R$ & $\begin{array}{c}-0.09 * * * \\
(-3.97)\end{array}$ & $\begin{array}{c}-0.08 * * * \\
(-2.85)\end{array}$ & $\begin{array}{c}0.00 \\
(0.15)\end{array}$ \\
\hline ODR & $\begin{array}{c}-0.21 * * * \\
(-2.89)\end{array}$ & $\begin{array}{c}0.86^{* * * *} \\
(3.53)\end{array}$ & $\begin{array}{c}-0.51 \\
(-0.61)\end{array}$ \\
\hline$O G$ & $\begin{array}{c}-0.44 * * * \\
(-4.46)\end{array}$ & $\begin{array}{c}-0.39 * * * \\
(-11.43)\end{array}$ & $\begin{array}{c}-0.38 * * * \\
(-5.35)\end{array}$ \\
\hline Adjusted $R^{2}$ & 0.40 & 0.61 & 0.46 \\
\hline
\end{tabular}

(Source: authors' estimates)

$(()=\mathrm{T}$ statistics; $* * *=$ significant at $1 \%, * *=$ significant at $5 \%, *=$ significant at $10 \%)$

(Coefficients robust to heteroskedasticity)

\subsection{The simulated equilibrium current balances}

In simulating equilibrium current balances, we use the value of initial stocks of net foreign asset at the beginning of each four years period's and four years average values of dependency ratios and exclude output gap in order to remove short-term effects. Figure 1 shows the observed and equilibrium values of the current account for the main countries analyzed in the multinational model. Figure 2 gives the current account for the main Euro area's members.

The US current account target is between -2 and $-3 \%$ of GDP over the period. In several approaches on international imbalances, the target of $-3 \%$ of GDP is selected for the U.S. current account deficit in the medium term (Ahearne et al., 2007). The simulated target for the 
current account deficit of the United States thus appears consistent with approaches that set the standard deficit on an ad hoc basis.

Figure 1: Actual and equilibrium current accounts of the main industrialized countries (in $\%$ of GDP) $)^{2}$
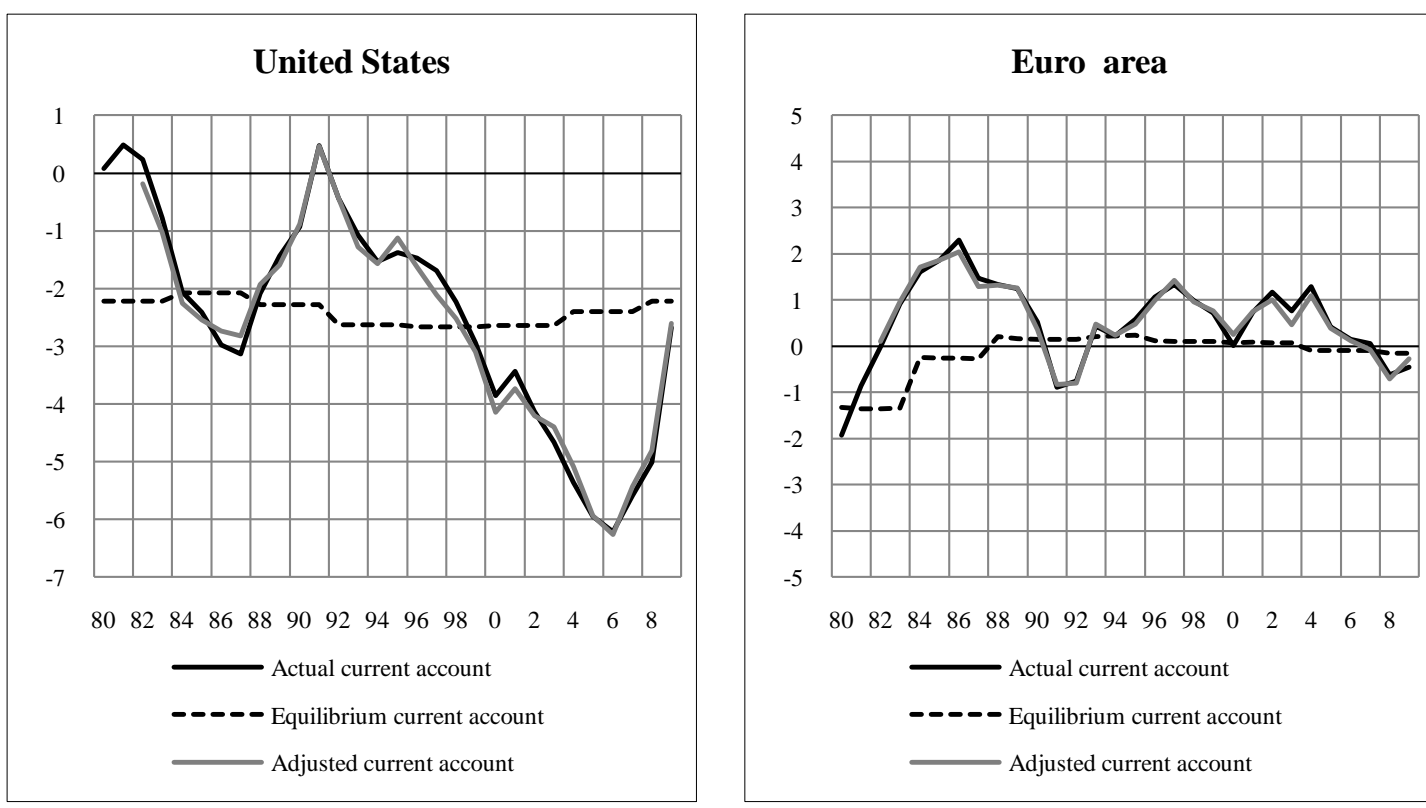

$\begin{array}{lllllllllllllll}80 & 82 & 84 & 86 & 88 & 90 & 92 & 94 & 96 & 98 & 0 & 2 & 4 & 6 & 8\end{array}$
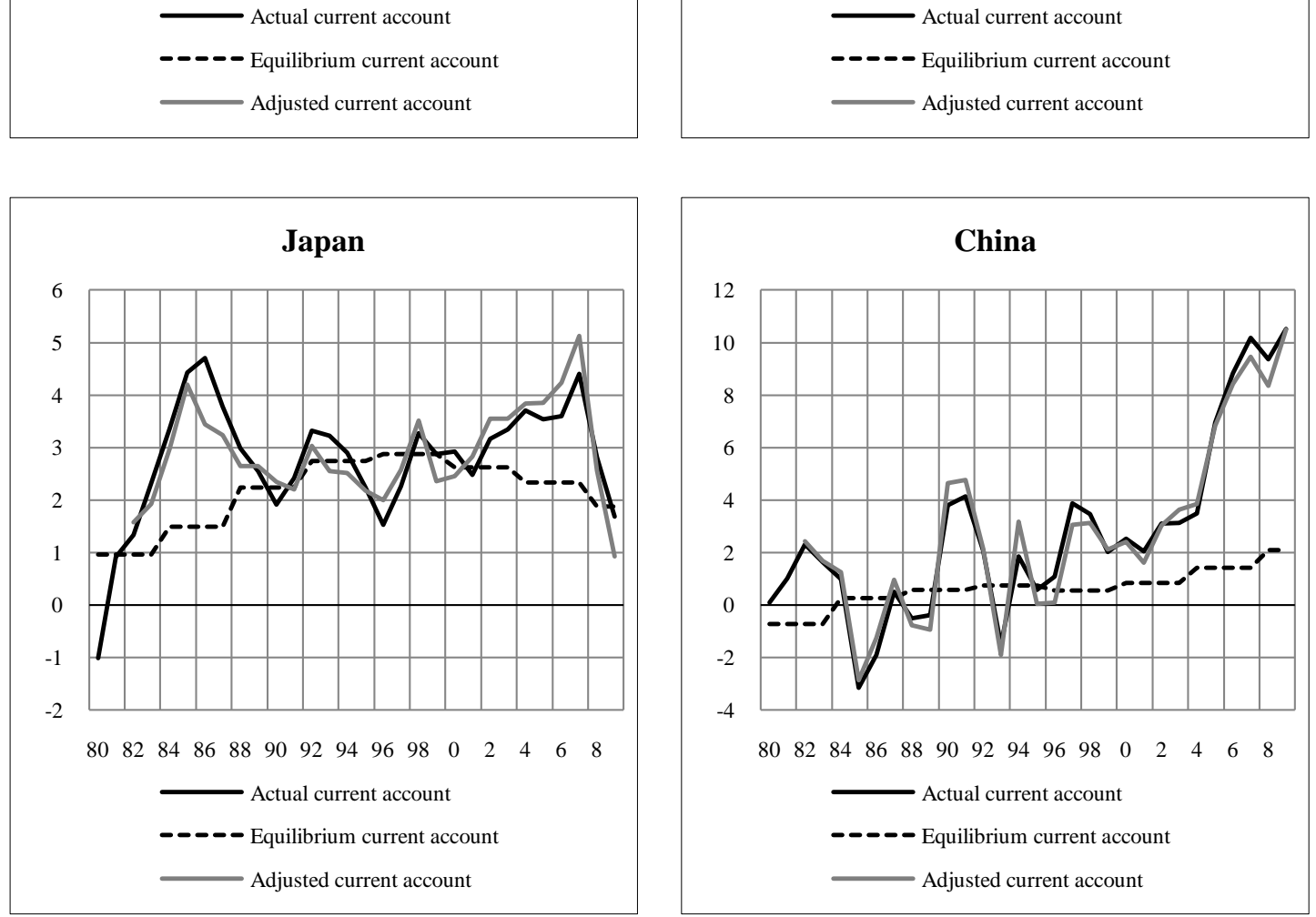

(Source: authors' calculation, International Monetary Fund (World Economic Outlook, April 2009) for the observed current account as \% of GDP, forecast for 2009)

\footnotetext{
${ }^{2}$ The observed current account of the main trade partners have been corrected from the global discrepancy proportionately to theirs weights in the world trade (Source: CHELEM; World Economic Outlook, April 2009 (International Monetary Fund)).
} 
Japan has experienced contrasting trends. Its equilibrium current account balance has increased until the mid-1990s under the effect of its improving net external position due to surpluses' accumulation. Then the Japanese equilibrium current account balance deteriorated due, mainly, to a sharp increase in the old dependency ratio (ODR) which reduced national savings since it increased the share of inactive with low saving ratio.

China had an equilibrium current account close to zero \% of GDP during the 1980s and the first years of 1990s, which seems coherent with the policy adopted by Chinese authorities that wanted to avoid the resort to large external debt. Since the mid-1990s, the equilibrium current account has increased to reach $2 \%$ of GDP in 2008. In this evolution the improvement of net external position and the decreasing of the child dependency ratio (CDR) played a positive role.

The current account of the Rest of the World is equal to the opposite of the sum of the other main countries' current accounts in dollars, as the global discrepancy at the world level has been eliminated. In percentage of GDP, it fluctuated around $-1 \%$ in the 1980-1990s and increased to $2 \%$ in the first half of the 2000 s, with huge surpluses of many emerging countries and oil producers. The Rest of the World's current account target is calculated, in the same way, as the opposite of the sum of the other countries' current account targets in dollars. This treatment guarantees the consistency of the current account targets at the world level, which is crucial in the FEER approach. In percentage of GDP, the Rest of the World's current account target has remained rather stable around $0.5 \%$ of GDP during the whole period, which is close to the target $(0 \%)$ generally used in the ad hoc approach (the current account targets of the other countries are presented in appendix 7).

Since the mid-1990s, the Euro area's equilibrium current account has been close to zero with a slight improvement over the early 1980s, thanks to a growing external position. The amplitude of current imbalances in the euro area (as a whole) is weak compared to those observed in other major world economies. However, this "balanced" situation in the Euro area masks a great heterogeneity for each Euro area's member. The Spanish, French and Italian current account deficits have contrasted, in recent years, with surpluses in Germany while their current account's targets were less in deficit. Since the mid-1990s, the equilibrium current account of France has even improved, thanks to more favorable demographic evolutions. By contrast, the German equilibrium current account has returned to 0\% of GDP 
as a result of the aging German population. The equilibrium current account of Italy and Spain have increased in the 1980s thanks to net external position improvement but they have deteriorated (in Italy) or stabilized (in Spain) around - 2\% of GDP, again due to a substantial aging of the population.

Figure 2: Actual and equilibrium current accounts of the main Euro area's members (in $\%$ of GDP)
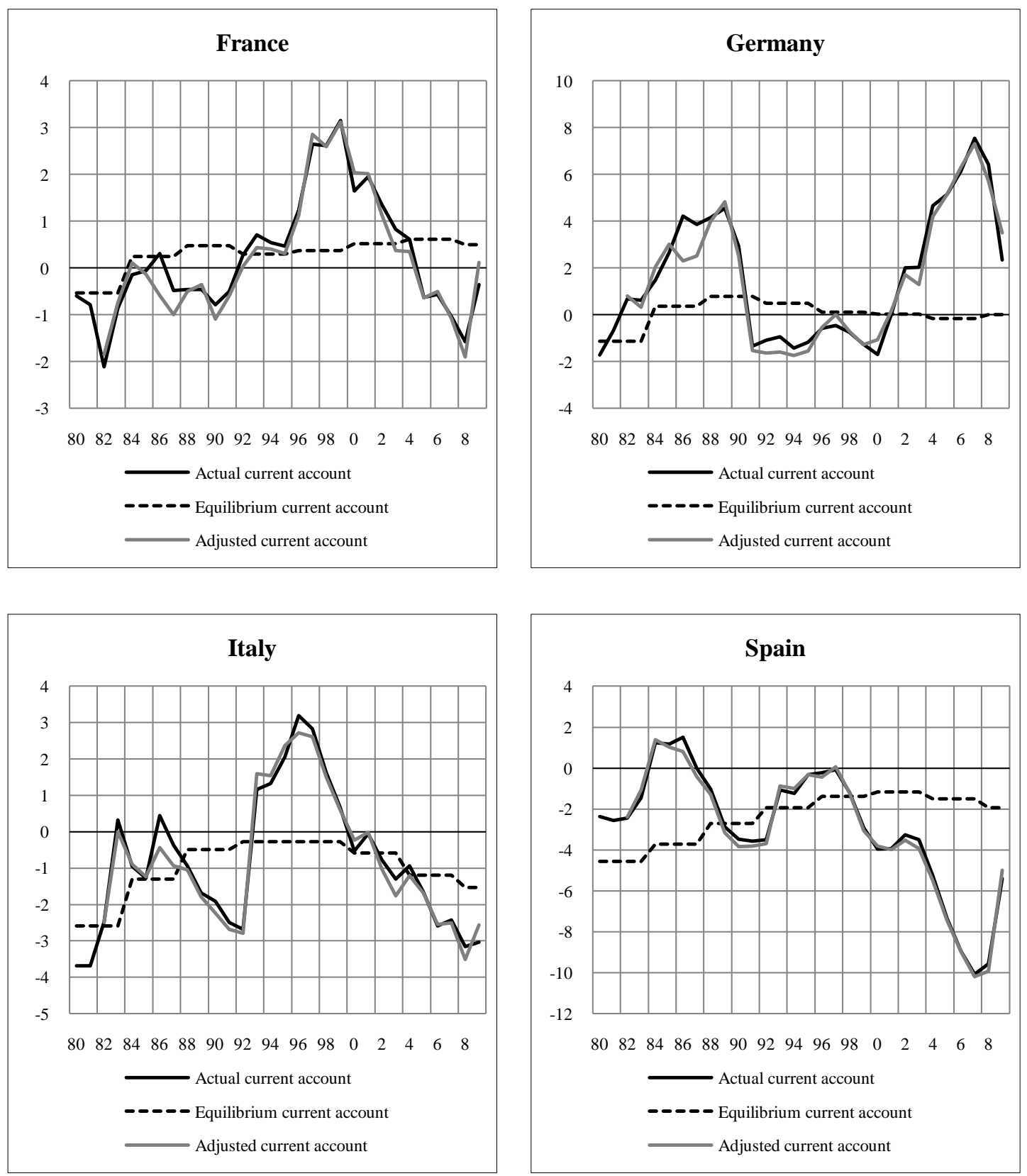

(Source: authors' calculation, International Monetary Fund (World Economic Outlook, April 2009) for the observed current account as \% of GDP, forecast for 2009)

A last correction should be specified. In the FEER theoretical framework, the whole difference between observed current balance and equilibrium one must not be interpreted 
entirely as an external disequilibrium. This difference is partly due to delayed effects of exchange rates variations that have not yet occurred entirely, but should be taking into account in the estimation. This correction is made using the dynamic structure of external trade equations. These figures show observed and adjusted current accounts with equilibrium ones (appendix 8).

\subsection{The estimation of internal equilibrium}

The internal equilibrium is defined as the state of full utilization of productive resources, without inflation pressures. For sake of simplification, a restrictive approach, limited to the measure of the potential output, is adopted. This approach of internal equilibrium seems less suited for emerging countries like China, where the concepts of potential output and full employment raise many problems, particularly because of the extent of regional imbalances and hidden underemployment in rural areas (Bouveret et al., 2006). This estimation of output gap is simply taken as representative of the degree of deviation of the internal demand (di). It must be regarded as a first step, which seems, however, sufficient at this stage. Indeed, as we shall see, results are only slightly sensitive to output gap's estimates. Different methods can be employed in calculating potential production and the corresponding output gap. For industrialized countries, we take the values estimated with production function by the $\mathrm{OECD}^{3}$. This approach relies on estimated productions functions and a measure of the available productions factors in the country. It demands more informations and more hypotheses regarding economic mechanisms than other simpler approaches, but is less mechanical and is theoretically more relevant.

For developing countries, this kind of estimates is not avalaible. So we calculate output gap by using the Hodrick-Prescott filter on real GDP over the period 1970-2013 ${ }^{4}$. However, a study in depth on this issue found that output gaps of East Asian countries estimated by several methods are similar for the period 1975-2000 (Gerlach and Yiu, 2004). In addition,

\footnotetext{
${ }^{3}$ Economic Outlook, OECD, December 2008.

${ }^{4}$ As it is known, this filter has certain disadvantages. It does not define well the output gap at the beginning and at the end of samples. It tends to neglect the structural breaks and the regime shifts. For prolonged slowdowns it deviates too much from a production function gap. We use the Hodrick-Prescott filter with a lower smoothing parameter than that of industrialized countries to take into account that the business cycle is shorter in emerging countries.
} 
our sensitivity tests show that errors in output gap estimation do not disrupt the whole conclusion. In the case of China, an increase of $1 \%$ in output gap leads to less than $1 \%$ of undervaluation.

\section{Equilibrium exchange rates and misalignments}

\subsection{Estimates of FEER for the main economic partners}

With the internal and external equilibrium previously estimated, the multinational model for the main economic partners is used six times to produce misalignments in terms of real effective exchange rates $\left(r=d \log R=d R / R=\left(R-R^{e}\right) / R^{e}\right)$ and nominal exchange rate against the dollar $\left(e=d \log E=d E / E=\left(E-E^{e}\right) / E^{e}\right)$, each country playing successively the role of residual country without its own current account target. The final solution is obtained by making an average of the 5 runs in which the current account target of each country is included (designated OCI for own country included).

This allows determining undervaluations $(e>0$ and $r>0$ ) or overvaluations $(e<0$ and $r<0$ ) for the dollar, the euro, the yen, the yuan, the pound sterling and the Rest of the World's currency over the period 1994-2009. The results are presented in table 3. Figures 3 and 4 show the evolution of the observed and equilibrium exchange rate over the period, in real effective and nominal bilateral against the dollar terms.

In real effective terms, the dollar appeared undervalued in the middle of the 1990s (around 9\%). Yet, this undervaluation decreased with the dollar's real appreciation and the American currency became overvalued (11\% in 2001). Since then, in spite of its real depreciation, the dollar appeared more and more overvalued (reaching 30\% in 2005 and 2006). This reflected the growing American imbalances and the structural loss of American competitiveness which was illustrated by an even stronger real depreciation of the dollar's equilibrium exchange rate. After the crisis erupted in 2007, the real overvaluation of the dollar has been reduced and may reach $8 \%$ in $2009^{5}$.

\footnotetext{
${ }^{5}$ Forecast based on the World Economic Outlook, International Monetary Fund, April 2009.
} 
Table 3: Undervaluation (e $>0$ and $r>0$ ) or overvaluation $(e<0$ and $r<0$ ) for Japan, China, the U. S., the Euro area, the U. K. and the Rest of the World (in \%)

\begin{tabular}{c|ccccc|cccccc}
\hline & \multicolumn{6}{|c|}{ Nominal Bilateral } & \multicolumn{7}{c}{ Real Effective } \\
\hline & ejp & ech & eeu & euk & erow & rjp & rch & rus & reu & ruk & rrow \\
\hline $\mathbf{1 9 9 4}$ & -2.5 & 17.3 & -5.5 & -1.6 & -3.4 & -0.8 & 18.6 & 7.1 & -3.4 & 2.0 & 0.1 \\
$\mathbf{1 9 9 5}$ & -10.6 & -7.4 & -6.6 & -7.2 & -10.6 & -3.4 & 0.8 & 8.5 & 1.2 & 0.0 & -4.1 \\
$\mathbf{1 9 9 6}$ & -14.7 & -9.9 & -5.6 & -8.2 & -13.5 & -4.7 & 0.7 & 3.7 & 4.2 & -0.1 & -5.4 \\
$\mathbf{1 9 9 7}$ & -10.2 & 7.1 & -3.4 & -5.3 & -10.3 & -2.7 & 14.5 & 0.0 & 3.5 & 0.7 & -3.7 \\
$\mathbf{1 9 9 8}$ & -10.7 & 7.4 & -6.7 & -4.4 & -10.7 & -2.8 & 16.0 & -1.5 & 0.6 & 3.4 & -3.0 \\
$\mathbf{1 9 9 9}$ & -14.3 & 1.8 & -3.8 & -5.6 & -7.5 & -8.9 & 8.5 & -4.3 & 2.0 & -0.5 & -2.4 \\
$\mathbf{2 0 0 0}$ & -2.1 & 8.8 & 3.6 & 3.7 & 5.3 & -5.0 & 6.1 & -13.0 & 0.1 & 0.6 & 3.1 \\
$\mathbf{2 0 0 1}$ & 2.3 & 5.2 & 11.8 & 4.5 & 7.9 & -1.4 & 1.0 & -11.0 & 6.8 & -2.6 & 2.7 \\
$\mathbf{2 0 0 2}$ & 9.7 & 16.4 & 15.2 & 6.5 & 13.6 & 2.4 & 7.1 & -16.3 & 6.6 & -3.9 & 4.8 \\
$\mathbf{2 0 0 3}$ & 15.9 & 23.0 & 15.1 & 9.2 & 20.8 & 4.0 & 8.4 & -17.7 & 2.2 & -3.9 & 8.8 \\
$\mathbf{2 0 0 4}$ & 23.9 & 25.5 & 22.9 & 12.5 & 22.0 & 7.4 & 6.9 & -24.1 & 6.0 & -6.1 & 6.2 \\
$\mathbf{2 0 0 5}$ & 32.3 & 41.7 & 22.6 & 17.9 & 29.4 & 8.7 & 15.7 & -30.6 & -0.4 & -4.1 & 9.2 \\
$\mathbf{2 0 0 6}$ & 35.6 & 47.4 & 22.1 & 18.0 & 29.9 & 10.3 & 19.6 & -31.9 & -1.7 & -4.5 & 8.7 \\
$\mathbf{2 0 0 7}$ & 27.7 & 39.7 & 10.8 & 11.5 & 17.9 & 11.3 & 21.9 & -23.3 & -4.1 & -1.0 & 5.1 \\
$\mathbf{2 0 0 8}$ & 21.6 & 35.3 & 11.0 & 12.5 & 20.5 & 4.8 & 17.1 & -22.8 & -4.9 & -0.9 & 7.5 \\
$\mathbf{2 0 0 9}$ & 4.4 & 29.3 & 3.9 & 1.5 & 7.8 & -1.5 & 24.1 & -7.7 & -1.5 & -2.7 & 4.3 \\
\hline (Source: authors' calculations, forecast for 2009) & & & & & & &
\end{tabular}

The euro real effective exchange rate's evolution is rather opposite to the dollar's one. From the mid-1990s to 2000, the euro has depreciated in real effective terms but remained close to its equilibrium value, which depreciated also, reflecting the problems of European competitiveness during this period. Since 2000, the euro became undervalued in real terms (7\% in 2001) in spite of its real appreciation, thanks to painful structural adjustments, mainly in Germany, which induced a real appreciation of the euro equilibrium exchange rate. With ongoing real revaluation, the euro real undervaluation has declined and has been replaced from 2005 by a slight overvaluation.

In spite of its real appreciation, since 1994, the yuan has been undervalued in real effective terms (16\% in 1998). This result is explained by the real revaluation of its equilibrium exchange rate, reflecting the important progress of the Chinese competitiveness. This undervaluation has been temporarily reduced after the Asian crisis and the large devaluations of most of the East Asian competitors. 
Figure 3: Actual and equilibrium real effective exchange rates $(2000=100)$
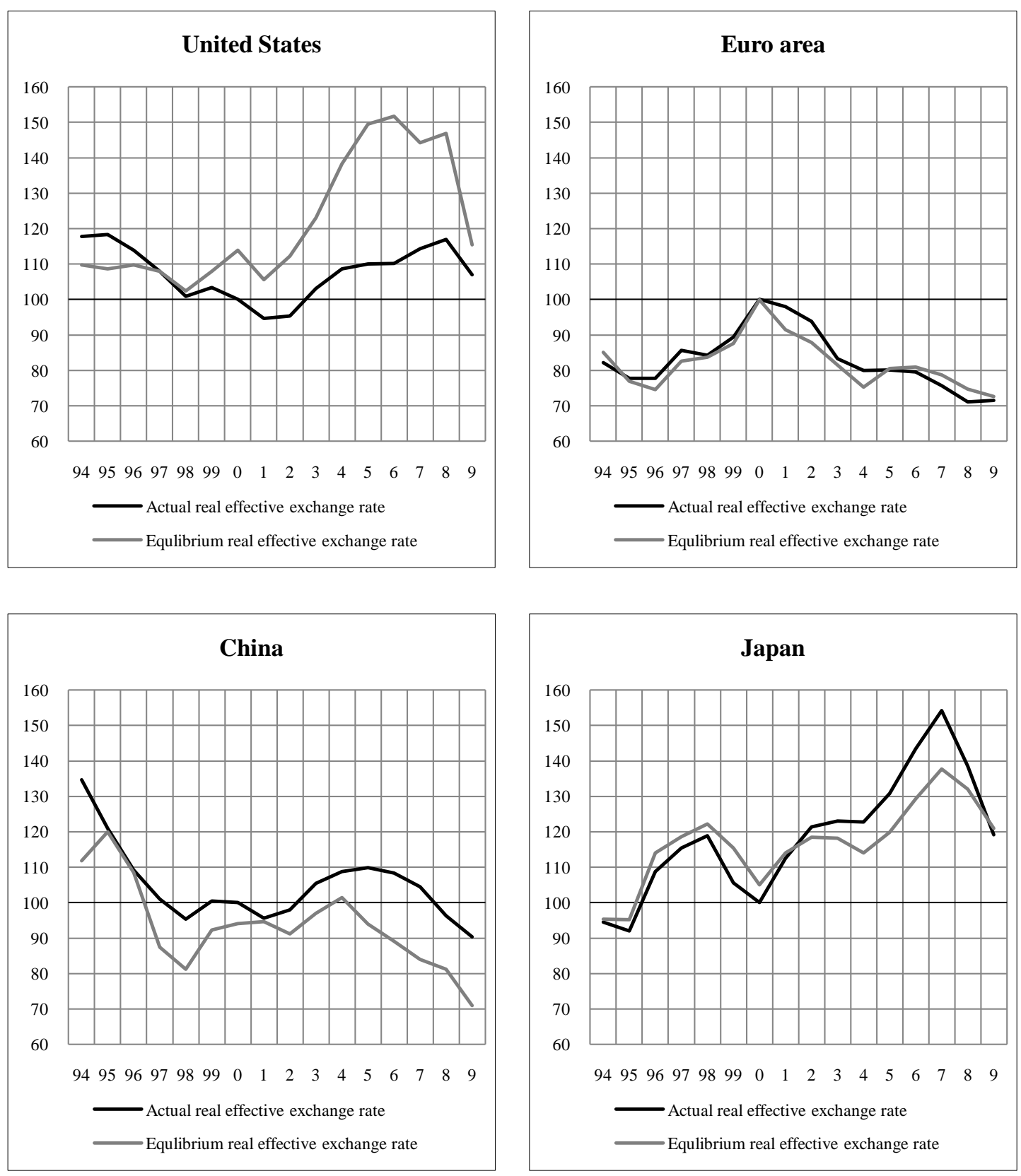

(Source: authors' calculations, Bank for International Settlements for the real effective exchange rate (annual average of monthly data), partial data for 2009)

In nominal bilateral term against the dollar, rather convergent observations can be done. The euro, the yen and the pound sterling were overvalued from 1994 to 1998, although the first two have depreciated. This reflected the undervaluation of the dollar during the second half of the 1990s. The yuan was the only exception with an undervaluation against the dollar, although attenuated by the Asian crisis's consequences. After 2000 all the currencies became undervalued against the dollar (22\% for the euro, $47 \%$ for the yuan, $36 \%$ for the yen and $18 \%$ for the pound in 2006) in spite of the dollar depreciation. This reflected the growing 
imbalances of the U.S. economy which have led to a depreciation of the equilibrium exchange rate of the dollar. Following the crisis, the undervaluation has disappeared and all the currencies are close to their equilibrium value in 2009, except the yuan which remains undervalued.

Figure 4: Actual and equilibrium bilateral exchange rate against the dollar $(2000=100)$
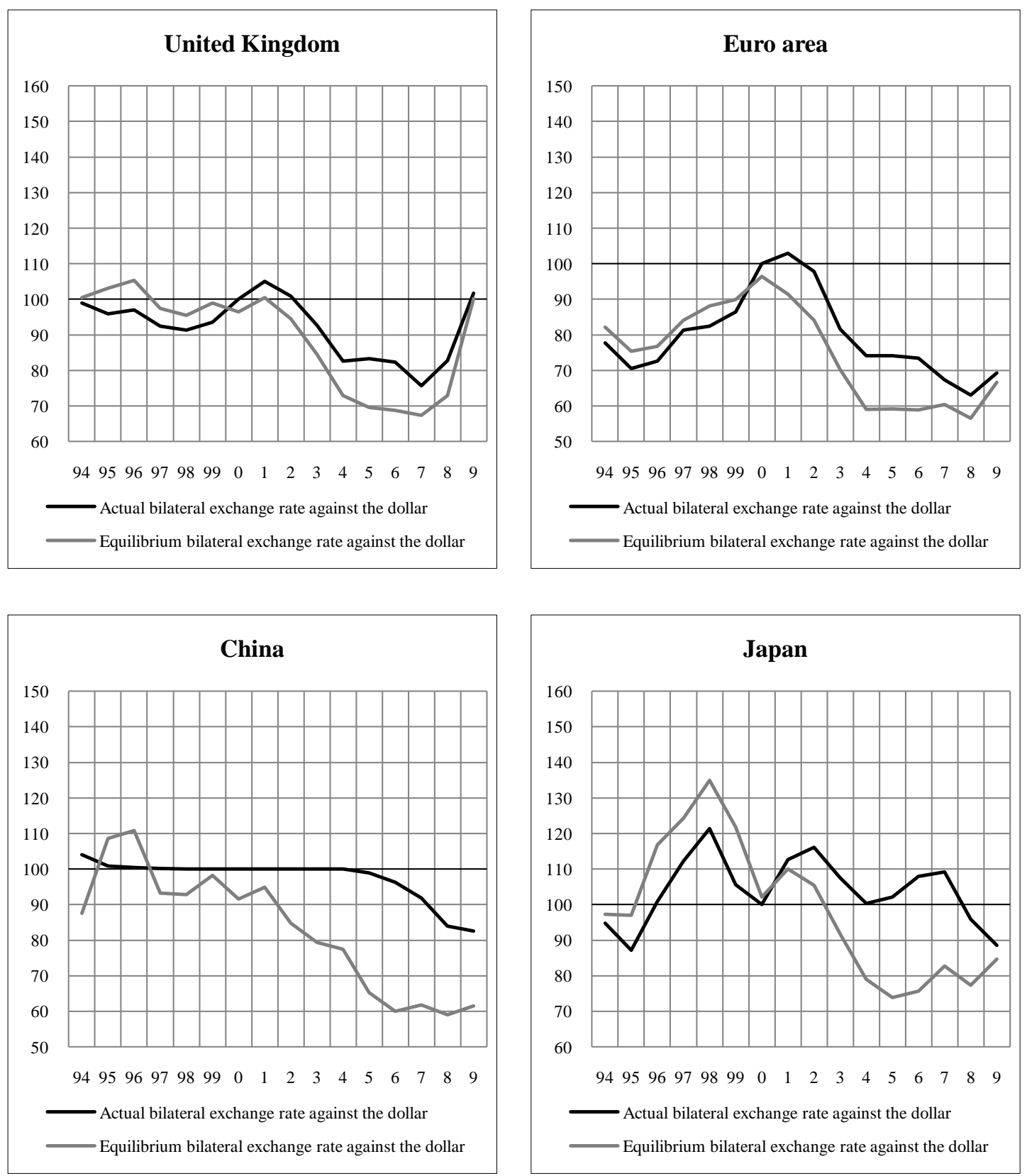

(Source: authors' calculations, OECD for bilateral exchange rates, partial data for 2009)

In spite of some differences in the methodology, a comparison with Cline's estimates is possible. If, in both cases, the FEER framework is used, Cline's model has 35 countries, a 
simpler analysis of the foreign trade for each country and no structural approach of the current account equilibrium. Instead, it is simply supposed that external imbalances should not exceed $3 \%$ of GDP (in absolute value) in the medium term, which allows building a scenario of current account targets for the 30 non-oil exporting countries.

Table 4: Comparison with Cline's estimates (in \%)

\begin{tabular}{|c|c|c|c|c|c|c|}
\hline \multicolumn{2}{|c|}{ REER } & USA & $\boldsymbol{E U}$ & CHN & $J P N$ & $U K$ \\
\hline \multirow{2}{*}{2008} & Our results & -22.8 & -4.9 & 17.1 & 4.8 & -0.9 \\
\hline & Cline & -7.8 & -4.3 & 12.6 & 4.2 & -4.2 \\
\hline \multirow{2}{*}{2009} & Our results & -7.7 & -1.5 & 24.1 & -1.5 & -2.7 \\
\hline & Cline & -17.4 & -0.9 & 21.4 & -1.2 & -0.6 \\
\hline \multicolumn{2}{|c|}{ BILATERAL } & $U S A$ & $\boldsymbol{E} \boldsymbol{U}$ & CHN & $J P N$ & $U K$ \\
\hline \multirow{2}{*}{2008} & Our results & - & 11.0 & 35.3 & 21.6 & 12.5 \\
\hline & Cline & - & 2.7 & 23.4 & 15.1 & 1.0 \\
\hline \multirow{2}{*}{2009} & Our results & - & 3.9 & 29.3 & 4.4 & 1.5 \\
\hline & Cline & - & 17.1 & 40.2 & 19.2 & 16.2 \\
\hline
\end{tabular}

(Source: Cline, 2008; Williamson and Cline, 2009; authors' calculations, forecast for 2009)

(A positive number indicates an undervaluation. Conversely, a negative number indicates an overvaluation)

Our results are close to those of Cline, in real effective terms, with some divergence regarding the dollar which can be understood (table 4). In both cases the overvaluation of the euro in real effective terms remained small in 2008 and 2009, which can be explained by a limited current account deficit, close to its equilibrium value. For the dollar results are more divergent, which has an incidence on all the estimated nominal bilateral misalignments against the dollar. The discrepancy in 2008 and 2009 with Cline's results for the real effective misalignment of the dollar is mainly explained by differences in the US current account target. In a previous estimation for 2008, we had a target close to -3\% of GDP (as in Cline's work) and results gave a more limited overvaluation of $-11.1 \%$ for the dollar in 2008 . However, the actual estimation with an overvaluation of $-22 \%$ seems plausible as the US current deficit was still -5\% of GDP in 2008. For 2009 results are provisional and rely on different forecasts for 2009. Specifically, we have retained the IMF forecast of the US current deficit $(-2.8 \% \text { of GDP })^{6}$ whereas Cline used a specific model to assess the U.S. current

\footnotetext{
${ }^{6}$ International Monetary Fund, World Economic Outlook, April 2009.
} 
account deficit in the medium term (Cline and Williamson, 2009). He selected a forecast of the U.S. deficit of about $-6 \%$ which explained the stronger overvaluation. For 2009, our estimation gave a smaller overvaluation of the dollar than in 2008 in spite of the dollar real appreciation, which can be linked to the sharp reduction of the US deficit.

Last, the question of the gap between ex ante and ex post current account targets can be examined. In a previous methodology (Jeong and Mazier, 2003), the ex ante and ex post current account targets were equal for all the countries or areas of the world model, except for the Rest of the World since it was treated as a residual. In this article, we have treated symmetrically all the countries of the trade model (Rest of World included) like in Cline (2008). All the countries or areas are treated successively as a residual. In this new methodology, the ex ante and ex post current account targets are slightly different. But the average deviation remains inferior to $0.3 \%$ of GDP (in absolute value) for the period 20042009 (appendix 9).

\subsection{European disparities}

Beyond estimates of misalignments for the whole euro area, intra-European disparities must be examined in more details. The misalignments are not of the same magnitude at the level of each European country due to the important heterogeneity which remains significant. The two most obvious sources of heterogeneity regarding exchange rates are the foreign trade structure, which differs largely among European country, and the inequality between national rates of inflation, which is less important, but not negligible. These two sources of heterogeneity explain the dispersion of effective exchange rates in nominal and real terms, as shown in Figure 5.

The first point to underline is that effective exchange rates are more stable at the level of each national country than at the level of the whole euro area because the importance of intraEuropean trade with fixed exchange rates stabilizes the effective exchange rate. Between 2001 and 2008 the euro appreciation has been more limited at the national level than at the whole euro area level. This function of stabilization of the euro is an important argument in favor of monetary unification.

The second point is the dispersion between countries. In nominal terms, Germany has suffered of the strongest appreciation since 2001, due to the importance of the extra-European trade for 
this country, while, on the contrary, the euro appreciation was more limited in Spain where intra-European trade occupies a larger share. For real effective exchange rates, which are crucial for competitiveness, it is the opposite. The dispersion is more noticeable between countries, due to the divergence between rates of inflation. In this case, Germany suffered of the smallest appreciation, thanks to its low relative rate of inflation, while Spain has faced a stronger real appreciation.

Figure 5: Nominal and real effective exchange rates $(2000=100)$
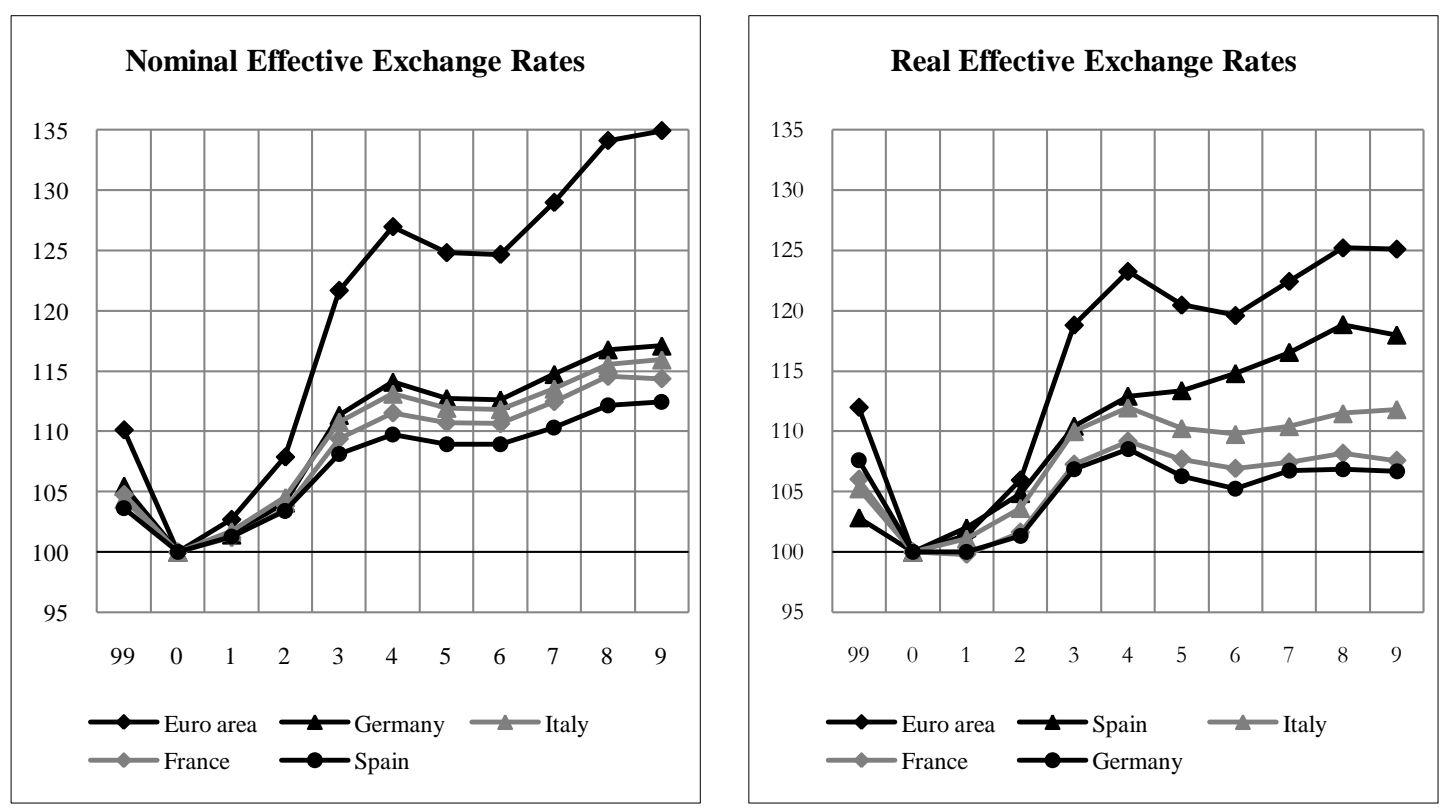

(Source: Bank for International Settlements (annual average of monthly data), partial data for 2009)

These divergences have an important impact on growth and employment in each country. But European heterogeneity covers a larger set of factors, such as the quality of the international specialization, the non-price competitiveness parameters, the efficiency of the national system of innovation, the nature of wage relations or the characteristics of the financial system and its links with the productive sector. All these institutional forms indirectly influence national economic performances. In a sense, they are reflected in the level and evolution of equilibrium exchange rates as they can be estimated for each European country. Like in the case of the main currencies, the following tables present the overvaluation $(r<0, e<0)$ or undervaluation $(r>0, e>0)$ for each "national euro" for the period 1994-2009 in real effective terms (table 5) and bilateral terms against the dollar (table 6). Sensitivity tests are given in appendix 10 to appreciate the dependency on the estimates of external and internal equilibrium and on the parameters of the trade model. 
The weighted sum (by the GDP) of the intra-European misalignments is equal to the euro misalignment. Our estimates of intra-European misalignments are derived from the national models. The weighted sum of these misalignments is close to the euro misalignment derived from the world model. When there was a discrepancy, we have distributed the difference (between misalignments of the euro and the weighted sum of intra-European misalignments) proportionately to the weight of the country in the euro area GDP (appendix 11).

First, it appears that misalignments for each "national euro" are quite different from what is observed for the euro itself. The misalignments of the euro in real effective terms are more limited, specially the undervaluation at the beginning of the 2000s and the overvaluation which has followed. This is in clear contrast with the national misalignments. Consequently, the constraints exerted on each European country by the euro exchange rate policy are very different (appendix 12).

Second, the relative position of each "national euro", in terms of misalignments, is not permanent and can vary in the medium to long-run according to structural adjustments which affect each economy. The cases of Germany and France are interesting to examine first in that perspective. In the mid-1990s, the "euro-mark", which was in fact the Deutschmark at that time, was overvalued (nearly $7 \%$ in real effective terms, around $18 \%$ against the dollar) because of the consequences of the German reunification. This required a substantial transfer of resources from West to East Germany, induced a drift of unit costs and significantly reduced the German external surplus. At the official launching of the euro in 1999 the "euromark" was still overvalued. This contrasted with the position of the global euro which, at that time, was close to equilibrium. Since the late 1990s, the German economy has realized a painful adjustment process by cost reducing and industrial restructuring with delocalization of activities. This strategy has significantly slowed down economic growth in Europe during this period but helped to rebuild new foundations for German competitiveness. As a consequence, since the mid-2000s, the "euro mark" has become undervalued (around $18 \%$ in real effective terms, around $35 \%$ against the dollar) while the euro, for the whole area, became overvalued.

France is, for a large part, in an opposite situation. In the second half of the 1990s, the "eurofranc" was undervalued (by almost $12 \%$ in real effective terms and against the dollar). France took advantage of the German economic difficulties and of its long run strategy of competitive disinflation. This situation did not last. Since the mid-2000s, the "euro franc" 
became more and more overvalued in contrast with a global euro close to its equilibrium value. This induced strong constraints on the French economy during this period and reflected structural problems of competitiveness which had remained unsolved since the 1990s. These problems had only been reduced by the German transitory difficulties following the reunification and by the disinflation strategy, which turned to be only a short term solution, without solving more structural handicaps.

Table 5: Undervaluation ( $\mathrm{rc}>0)$ or overvaluation $(\mathrm{rc}<0)$ for each "national euro" in real effective terms (in \%)

\begin{tabular}{c|c|ccccccccc}
\hline $\boldsymbol{r C}$ & $\boldsymbol{E} \boldsymbol{U}$ & $\boldsymbol{F R A}$ & $\boldsymbol{G E R}$ & $\boldsymbol{I T A}$ & $\boldsymbol{S P A}$ & $\boldsymbol{A U T}$ & $\boldsymbol{F I N}$ & $\boldsymbol{I R L}$ & $\boldsymbol{N L D}$ & $\boldsymbol{P R T}$ \\
\hline $\mathbf{1 9 9 4}$ & -3.4 & -2.0 & -11.6 & 6.7 & 4.4 & -3.5 & -3.2 & 2.7 & -3.3 & 4.4 \\
$\mathbf{1 9 9 5}$ & 1.2 & 0.1 & -6.4 & 11.9 & 13.0 & -4.9 & 9.8 & 7.0 & 1.3 & 13.6 \\
$\mathbf{1 9 9 6}$ & 4.2 & 5.3 & -0.5 & 12.6 & 7.2 & -4.1 & 13.0 & 5.4 & 1.8 & -4.3 \\
$\mathbf{1 9 9 7}$ & 3.5 & 12.9 & -2.9 & 7.3 & 4.0 & -7.6 & 16.0 & 1.3 & -0.1 & -17.1 \\
$\mathbf{1 9 9 8}$ & 0.6 & 12.0 & -6.1 & 3.4 & -2.0 & -3.9 & 15.6 & -2.6 & -4.3 & -20.7 \\
$\mathbf{1 9 9 9}$ & 2.0 & 19.0 & -6.0 & 2.8 & -8.2 & -1.1 & 19.2 & 1.0 & 0.6 & -24.7 \\
$\mathbf{2 0 0 0}$ & 0.1 & 10.2 & -4.1 & 1.3 & -12.0 & 4.2 & 25.1 & -0.9 & -0.3 & -29.4 \\
$\mathbf{2 0 0 1}$ & 6.8 & 16.1 & 6.4 & 7.4 & -8.8 & 5.5 & 32.9 & 3.7 & 3.9 & -28.4 \\
$\mathbf{2 0 0 2}$ & 6.6 & 9.6 & 11.6 & 3.7 & -7.9 & 16.1 & 32.5 & 3.0 & 1.6 & -20.4 \\
$\mathbf{2 0 0 3}$ & 2.2 & 2.1 & 7.7 & -0.6 & -10.7 & 7.5 & 18.7 & 1.2 & 3.9 & -13.4 \\
$\mathbf{2 0 0 4}$ & 6.0 & 2.6 & 17.8 & 4.9 & -16.9 & 8.3 & 22.5 & 3.0 & 8.3 & -17.9 \\
$\mathbf{2 0 0 5}$ & -0.4 & -7.6 & 17.1 & -0.1 & -32.5 & 7.0 & 11.2 & -2.3 & 6.0 & -31.1 \\
$\mathbf{2 0 0 6}$ & -1.7 & -6.9 & 18.6 & -3.1 & -42.3 & 8.2 & 12.9 & -3.4 & 7.0 & -33.9 \\
$\mathbf{2 0 0 7}$ & -4.1 & -12.2 & 20.7 & -2.6 & -54.6 & 10.2 & 11.7 & -10.8 & 5.4 & -31.2 \\
$\mathbf{2 0 0 8}$ & -4.9 & -15.3 & 19.5 & -1.4 & -53.5 & 11.2 & 8.5 & -7.5 & 6.2 & -41.6 \\
$\mathbf{2 0 0 9}$ & -1.5 & -2.0 & 10.3 & -3.7 & -23.4 & 8.2 & 3.6 & -8.0 & 1.0 & -24.4 \\
\hline (Source: authors' calculations, forecasts for 2009$)$ & & & & & &
\end{tabular}

Spain and Italy are other interesting cases to examine. Following the devaluations that took place during the European Monetary System crisis, the peseta and the lira were undervalued during the second part of the 1990s (nearly 12\% in real effective terms, less in bilateral terms against the dollar). But, like for the French franc, this did not last. After the launching of the euro, we observed an overvaluation of the "euro-peseta" and, to a lesser extent, of "euro-lira", which has strengthened. This overvaluation reflected large inequalities of competitiveness inside the euro area. Actually constraints were less important in the case of Italy than in the 
case of Spain, with the housing bubble during the first half of the 2000s. The large overvaluation of the "euro peseta" (over $50 \%$ in 2008, in real effective terms) was largely related to insufficient productivity and weaknesses in $R \& D$ in a context of unsustainable economic growth. Portugal is another case of Southern European economy affected by the overvaluation of its currency since the second half of the 1990s. With a weak productivity, a peripheral localization and a specialization in low costs products, the Portuguese economy has never succeeded to invert this situation within the constraints of the euro area.

Table 6: Undervaluation $(\mathrm{e}>0)$ or overvaluation $(\mathrm{e}<0)$ for each "national euro" in nominal terms against the dollar (in \%)

\begin{tabular}{c|c|ccccccccc}
\hline $\boldsymbol{e}$ & $\boldsymbol{E U}$ & $\boldsymbol{F R A}$ & $\boldsymbol{G E R}$ & $\boldsymbol{I T A}$ & $\boldsymbol{S P A}$ & $\boldsymbol{A U T}$ & $\boldsymbol{F I N}$ & $\boldsymbol{I R L}$ & $\boldsymbol{N L D}$ & $\boldsymbol{P R T}$ \\
\hline $\mathbf{1 9 9 4}$ & -5.5 & -0.1 & -17.8 & 5.6 & 7.2 & -7.4 & -6.2 & 3.0 & -5.8 & 4.3 \\
$\mathbf{1 9 9 5}$ & -6.6 & -4.6 & -18.1 & 4.6 & 12.1 & -15.8 & 5.6 & 0.7 & -6.3 & 11.1 \\
$\mathbf{1 9 9 6}$ & -5.6 & -0.6 & -17.2 & 6.6 & 8.5 & -18.0 & 2.9 & -1.7 & -9.5 & -10.4 \\
$\mathbf{1 9 9 7}$ & -3.4 & 9.1 & -16.4 & 4.7 & 6.6 & -18.4 & 10.0 & -1.9 & -6.4 & -23.7 \\
$\mathbf{1 9 9 8}$ & -6.7 & 7.9 & -18.6 & -1.8 & -1.4 & -14.1 & 10.2 & -9.0 & -12.7 & -28.9 \\
$\mathbf{1 9 9 9}$ & -3.8 & 16.3 & -16.8 & -1.1 & -6.9 & -9.1 & 15.8 & -5.4 & -5.2 & -31.7 \\
$\mathbf{2 0 0 0}$ & 3.6 & 15.6 & -5.5 & 6.7 & -0.4 & 7.5 & 32.8 & 3.9 & 4.0 & -30.5 \\
$\mathbf{2 0 0 1}$ & 11.8 & 23.0 & 6.8 & 13.4 & 4.7 & 9.7 & 39.9 & 7.0 & 8.6 & -24.5 \\
$\mathbf{2 0 0 2}$ & 15.2 & 19.1 & 16.3 & 12.3 & 10.0 & 25.7 & 42.3 & 8.1 & 7.8 & -7.9 \\
$\mathbf{2 0 0 3}$ & 15.1 & 15.4 & 17.4 & 12.3 & 11.4 & 19.3 & 30.9 & 10.4 & 14.0 & 6.4 \\
$\mathbf{2 0 0 4}$ & 22.9 & 20.2 & 31.9 & 20.8 & 7.8 & 25.8 & 40.5 & 15.6 & 23.9 & 4.2 \\
$\mathbf{2 0 0 5}$ & 22.6 & 13.9 & 38.3 & 23.0 & -1.8 & 30.2 & 33.6 & 15.9 & 28.1 & -5.3 \\
$\mathbf{2 0 0 6}$ & 22.1 & 14.3 & 41.3 & 21.4 & -11.8 & 32.7 & 36.9 & 16.0 & 30.7 & -6.8 \\
$\mathbf{2 0 0 7}$ & 10.8 & -0.9 & 35.4 & 12.4 & -33.6 & 25.8 & 26.4 & 1.0 & 19.6 & -11.1 \\
$\mathbf{2 0 0 8}$ & 11.0 & -11.7 & 39.4 & 17.8 & -32.3 & 30.1 & 26.7 & 6.0 & 23.5 & -18.3 \\
$\mathbf{2 0 0 9}$ & 3.9 & -17.8 & 28.2 & 8.4 & -20.3 & 19.5 & 13.2 & -4.5 & 11.9 & -30.1 \\
\hline (Source: authors' calculations, forecasts for 2009$)$ & & & & & &
\end{tabular}

On the opposite, Ireland is an illustration of a catch up strategy which has been more successful, at least until the beginning of the 2000s. Until this period, the exchange rate has remained close to its equilibrium. But, since 2002, the Irish economic growth has become more unbalanced with the housing bubble, although the overvaluation of the "Irish euro" remained rather limited. This illustrates the fact that small opened economies generally suffer less of exchange rate misalignments, as it can be understood with the equation (17), where the 
openness ratio plays a key role. However, the Portuguese case shows that this general rule may suffer of exception in cases of larger unbalances due to structural weaknesses.

Netherlands, Austria and Finland, three small opened Northern and Alpine European economies, sometimes labeled as social-democrat, are the last cases to be examined. Netherlands and Austria have kept their exchange rates close to equilibrium during most of the period, although the Austrian currency was slightly overvalued during the second half of the 1990s, due to stronger connections with Germany. On the contrary, the Finnish mark was more undervalued during the second half of the 1990s (around 15\% in real effective terms), thanks to a large devaluation after the crisis of 1991-1992. This undervaluation has been progressively reduced, but preserved due to structural improvement of Finish external performances and to increasing $R \& D$ effort.

To sum up, beyond estimates of exchange rate misalignments of the euro, important disparities are observed between "national euros". The euro misalignments do not represent a pertinent indicator for each national euro (appendix 13). The misalignments seem to be more important for each individual euro area member than for the whole euro area. More specifically, during the second half of the 2000s the undervalued "euro mark" contrasts with the overvalued "euro franc" and "euro peseta".

\section{Conclusion}

Current account imbalances have increased dramatically since the mid-1990s and were only partially reduced since the burst of the crisis in 2007. These imbalances partly reflect exchange rates misalignments, a fact that has been studied extensively in the literature. But these imbalances, which have increased in the 2000s, are also important inside the Euro area. This analysis cannot be reduced to simple estimates of euro misalignment at the world level because specific constraints exist for each national economy of the euro area. This paper has examined to what extent intra-European imbalances reflect exchange rates misalignments for each "national euro". Our main argument is that the misalignment of the euro is not a pertinent indicator for each European country.

A FEER approach has been followed, combining both our previous methodology and recent improvements (Cline, 2008) in order to solve the problem raised by the treatment of the residual country. By relying on panel regression techniques, equilibrium current accounts 
have been estimated for the main countries and for each member of the euro area. A two-step analysis has been adopted in order to estimate and compare misalignments, first at the world level for the global euro, second at the European level for each "national euro".

First, using a model of world trade, a FEER has been estimated for the main currencies. Our results have confirmed the overvaluation of the dollar and undervaluation of euro during the first half of the 2000s, which have been progressively reduced while a durable undervaluation of the yuan has remained since the second half of the 1990s. However in real effective terms the misalignments of the euro have remained limited, specially the overvaluation since the middle of the 2000s. This contrasts clearly with what can be observed at the level of each European country.

Second, a FEER has been estimated for each European country of the euro area, using simple national models and linking estimates of the national FEER to the multinational model to obtain bilateral misalignments of each "national euro". Results show that important disparities were observed between "national euros". The misalignments appeared more important for each individual euro area member than for the whole euro area. During the first half of the 2000s, the undervalued "euro mark" has contrasted with the overvalued "euro franc" and “euro peseta". Southern European countries have been more affected by overvaluation while small countries remained closer to exchange rate equilibrium.

More generally, the misalignments of each "national euro" have changed at medium-long run according to structural adjustments which occurred in each country. They have also been induced by asymmetric shocks (like after the German reunification during the 1990s) or specific growth regimes (like the housing bubble in Spain or Ireland in the 2000s).

Disparities between European countries had important consequences for the definition of economic policy at the EU level, since these countries were characterized by divergent forces. A durable overvaluation means a permanent handicap for the related economy which can be compensated only by painful adjustments (as was the case in Germany in the 1990s). To reduce these adjustment costs, there are no appropriate economic tools at the EU level, as might be structural funds for new activities or sectors undergoing restructuring. This could justify the use of structural policies at the national level, to compensate temporarily negative misalignments effects, but these types of polices are in contradiction with the currently 
prevailing rules at Community level. A durable undervaluation means, on the contrary, an advantage that may disappear gradually without structural progress (as in France in the second half of 1990s) or may be used to improve the quality of international specialization through the R\&D and policy incentives (e.g. Finland). In this perspective a cumulative advantage may be generated.

Lastly, these results for the 2000s lead us to note the similarities between the current situation of misalignments within the euro area and the situation observed during the 1980s, within the European Monetary System, when the undervaluation of the Deutschmark was counterbalanced by the overvaluation of other European currencies (Couharde and Mazier, 2001). 


\section{References}

[1] Ahearne, A., Cline, W.R., Lee, K.T., Park, Y.C., Pisani-Ferry, J., Williamson, J., 2007. Global Imbalances: Time for Action, Policy Brief 07-4, March, Peterson Institute for International Economics, Washington

[2] Anderton, R., Di Mauro, F., Moneta, F., 2004. Understanding the Impact of the External Dimension on the Euro Area, Occasional Paper n²12, avril, BCE, Francfort

[3] BÉNASSY-QuérÉ A., BÉREAu S. and MignON V., 2009. Taux de Change d’Équilibre : une Question d'Horizon, Revue Économique, vol. 60, mars, Presses de Sciences Po, Paris, pp. 657-666

[4] Borowski, D., Couharde, C., 2003. The Exchange Rate Macroeconomic Balance Approach: New Methodology and Results for the Euro, the Dollar, the Yen and the Pound Sterling, Open Economies Review, ${ }^{\circ} 14$, Kluwer Academic Publishers, Netherlands, pp. 169190

[5] Bouveret, A., Mestiri, S., Sterdyniak, H., 2006. La Valeur du Yuan. Les Paradoxes des Taux de Change d'Équilibre, Revue de l'OFCE, n ${ }^{\circ} 98$, juillet, Presses de Sciences Po, Paris, pp. 98-127

[6] BRILLET, J.L., 2000. A Workbook for the use of the Chinese annual model, INSEE, Paris

[7] Carton, B., Hervé, K. and Terfous, N., 2007. Méthodes d'Estimation des Taux de Change d'Equilibre Fondamentaux dans un Modèle de Commerce Bouclé, Document de travail No 2007-12, Décembre, DGPTE, Paris

[8] ChInN, M.D., PRASAD, E.S., 2003. Medium Term Determinants of Current Accounts in Industrial and Developing Countries: an Empirical Exploration, Journal of International Economics, 59, Elsevier, pp. 47-76

[9] Clark, P.B., MacDonald, R., 1998. Exchange Rates and Economic Fundamentals: A Methodological Comparison of BEERs and FEERs, Working Paper 98/00, March, International Monetary Fund, Washington

[10] CLINE, W.R., 2008. Estimating Consistent Fundamental Equilibrium Exchange Rates, Working Paper 08-6, July, Peterson Institute for International Economics, Washington

[11] Cline, W.R., Williamson, J., 2008. New Estimates of Fundamental Equilibrium Exchange Rates, Policy Brief 08-7, July, Peterson Institute for International Economics, Washington

[12] Cline, W.R., Williamson, J., 2009. 2009 Estimates of Fundamental Equilibrium Exchange Rates, Policy Brief 09-10, June, Peterson Institute for International Economics, Washington

[13] Couharde, C., Mazier, J., 2001. The Equilibrium Exchange Rates of European Currencies and the Transition to the Euro, Applied Economics, $\mathrm{n}^{\circ} 33$, Routledge, London, pp. $1795-1801$ 
[14] DÉES, S, 1999. The Role of External Variables in the Chinese Economy; Simulation from a Macroeconomic Model of China, Working Paper n¹999-09, juin, CEPII, Paris

[15] FARUQEe, H., ISARD, P. (Editors), 1998. Exchange Rate Assessment: Extensions to the Macroeconomic Balance Approach, IMF Occasional Paper ${ }^{\circ} 167$, International Monetary Fund, Washington

[16] Gerlach, S., YIU, M.S., 2004. Estimating Output Gaps in Asia: a Cross-Country Study, Journal of the Japanese and International Economies, Vol. 18, Issue 1, March, Elsevier, pp. 115-136

[17] Herve, K., 2000. Comparaison des Comportements d'Exportations entre la Zone Euro, les États-Unis et le Japon, Note, B2-00-145/KH, Direction de la Prévision, Paris

[18] JeOng, S.-E., MAZIER, J., 2003. Exchange Rate Regimes and Equilibrium Exchange Rates in East Asia, Revue Économique, vol. 54, septembre, Presses de Sciences Po, Paris, pp. $1161-1182$

[19] Kwack, S.Y., Ahn, C.Y., LeE, Y.S., 2007. Consistent Estimates of World Trade Elasticities and an Application to the effects of Chinese Yuan (RMB) Appreciation, Journal of Asian Economics, 18, Elsevier, pp. 314-330

[20] Lane, P.R., Milesi-Ferretti, G.M., 2007. The External Wealth of Nations Mark II: Revisited and Extended Estimates of Foreign Assets and Liabilities, 1970-2004, Journal of International Economics, 73, Elsevier, pp. 223-250

[21] Lee J., Milesi-Ferreti G.M., Ostry J.D., Prati A., and Ricci L.A., 2008. Exchange Rate Assessments: CGER Methodologies, IMF Occasional Papers n²61, April, International Monetary Fund, Washington

[22] MaZier, J., Saglio, S., 2008. Interdependency and Adjustments in the European Union, International Review of Applied Economics, 22:1, January, Routledge, London, pp. $17-44$

[23] MIMOSA, 1996. La Nouvelle Version de MIMOSA, Modèle de l'Économie Mondiale, Revue de l’OFCE, vol. 58, n 1 , Presses de Sciences Po, Paris, pp. 103-155

[24] NIESR, 1997. The World Model NIGEM, juillet, NIESR

[25] Pain, N., Mourougane, A., SÉdillot, F. and Le Fouler, L., 2005. The New OECD International Trade Model, OECD Working paper ${ }^{\circ} 440$, August, Organisation for Economic Co-operation and Development, Paris

[26] Stein, J.L., Allen, P.R. et al., 1997. Fundamental Determinants of Exchange Rates, Oxford: University Press

[27] Williamson, J., 1983. The Exchange Rate System. $1^{\text {st }}$ edition, $2^{\text {nd }}$ edition 1985 , Institute for International Economics, Washington

[28] Wren-Lewis, S., Driver, R.L., 1998. Real Exchange Rates for the Year 2000, May, Institute for International Economics, Washington 


\section{Appendix 1: Multinational model in differential logarithmic ${ }^{7}$}

Multinational model in logarithmic differentials $\left(x=d X / X=\left(X-X^{e}\right) / X^{e}\right)$ is transformed into:

$$
\begin{aligned}
& x_{i}=\eta x_{i} \sum_{j \neq i} \alpha_{i j} m_{j}+\varepsilon x_{i}\left(p m x_{i}-p x_{i}\right) \\
& p m x_{i}=\sum_{j \neq i} \lambda_{i j}\left(p x_{j}-e_{j}\right)+e_{i}
\end{aligned}
$$

$$
m_{i}=\eta m_{i} d i_{i}+\varepsilon m_{i}\left(p d_{i}-p m_{i}\right)
$$

$\operatorname{pmm}_{i}=\sum_{j \neq i} \mu_{i j}\left(p x_{j}-e_{j}\right)+e_{i}$

$$
\begin{aligned}
& \sum_{i} v x_{i}\left(x_{i}+p x_{i}-e_{i}\right)=\sum_{i} v m_{i}\left(m_{i}+p m_{i}-e_{i}\right) \\
& \sum_{i} w x_{i} x_{i}=\sum_{i} w m_{i} m_{i}
\end{aligned}
$$

$p x_{i}=\alpha x_{i} p m x_{i}+\left(1-\alpha x_{i}\right) p_{i}$

$p m_{i}=\alpha m_{i} p m m_{i}+\left(1-\alpha m_{i}\right) p d_{i}$

$p d_{i}=a_{i} p m_{i}+\left(1-a_{i}\right) p_{i}$

$r_{i}=e_{i}-p d_{i}+\sum_{j \neq i}\left(p d_{j}-e_{j}\right)$

$b_{i}=\mu_{i} T_{i}\left(1-\sigma_{\text {petx }_{i}}-\sigma_{x_{i}}\right)\left(p x_{i}+x_{i}-p m_{i}-m_{i}\right)$

With $w x, w m, v x, v m=$ the shares of each country in the world exports in volume, the world imports in volume, the world exports in value and the world imports in value, respectively; $T$ $=P X X / P M M=$ ratio of exportation to importation; $\mu=P M M / P Y=$ openness ratio; $F=$ net external position in dollars; $i=$ interest rates; $\sigma_{x}=i E F / P X X=$ ratio of external debt services to exports and $\sigma_{p e t x}=E P_{p e t} M_{p e} / P X X$, ratio of net oil imports on non-oil exports.

$7 \lambda_{i j}=\frac{X_{i \rightarrow j}}{X_{i}} ; \mu_{i j}=\frac{M_{i \leftarrow j}}{M_{i}} ; \alpha_{i j}=\frac{X_{i \rightarrow j}}{M_{j}} ; v_{i j}=\left(\frac{X_{i \rightarrow j}+M_{i \leftarrow j}}{X_{i}+M_{i}}\right)$ (Source: authors' calculations, CHELEM, CEPII's database). Here, we use natural logarithms in order to simplify calculations. This approximation is acceptable at first order and in the vicinity of equilibrium. 
The way the equation (9)' is derived should be explained:

$$
\begin{aligned}
& b_{i}=\left(\frac{B_{i}}{P_{i} Y_{i}}\right)-\left(\frac{B_{i}^{e}}{P_{i}^{e} Y_{i}^{e}}\right)=d\left(\frac{B_{i}}{P_{i} Y_{i}}\right)=\mu_{i} d\left(\frac{B_{i}}{P M_{i} M_{i}}\right) \\
& b_{i}=\mu_{i} d\left[\left(\frac{P X_{i} X_{i}}{P M_{i} M_{i}}\right)-1-\left(\frac{E P_{p e t} M_{p e t i}}{P X_{i} X_{i}}\right)\left(\frac{P X_{i} X_{i}}{P M_{i} M_{i}}\right)-\left(\frac{i_{i} E_{i} F_{i}}{P X_{i} X_{i}}\right)\left(\frac{P X_{i} X_{i}}{P M_{i} M_{i}}\right)\right] \\
& b_{i}=\mu_{i} d T_{i}\left(1-\sigma_{\text {petxi }}-\sigma_{x i}\right)
\end{aligned}
$$




\section{Appendix 2: National model in differential logarithmic}

National model in logarithmic differentials $\left(x=d X / X=\left(X-X^{e}\right) / X^{e}\right)$ is transformed into:

$$
\begin{aligned}
& x_{i}=\eta x_{i} d_{i}^{*}+\left(1-\alpha x_{i}\right) \varepsilon x_{i} r_{i} \\
& m_{i}=\eta m_{i} d i_{i}-\left(\alpha m_{i} \varepsilon m_{i}\right) r_{i} \\
& p x_{i}=\alpha x_{i} r_{i}+p_{i} \\
& p m_{i}=\alpha m_{i} r_{i}+p_{i} \\
& b_{i}=\mu_{i} T_{i}\left(1-\sigma_{p e t x i}-\sigma_{x i}\right)\left(p x_{i}+x_{i}-p m_{i}-m_{i}\right)
\end{aligned}
$$

We can compute $r$, the misalignment of "national euro" in real effective terms $(r=d \log R=$ $\left.d R / R=\left(R-R^{e}\right) / R^{e}\right):$

$$
\begin{aligned}
& \frac{d T_{i}}{T_{i}}=p x_{i}+x_{i}-p m_{i}-m_{i} \\
& \frac{d T_{i}}{T_{i}}=\left(\eta x_{i} d_{i}^{*}-\eta m_{i} d i_{i}\right)+\left[\left(1-\alpha x_{i} \varepsilon x_{i}\right)+\varepsilon m_{i} \alpha m_{i}+\alpha x_{i}-\alpha m_{i}\right] r_{i} \\
& b_{i}=\mu_{i} d T_{i}\left(1-\sigma_{p e t x i}-\sigma_{x i}\right) \\
& \frac{d T_{i}}{T_{i}}=\frac{b_{i}}{\mu_{i} T_{i}\left(1-\sigma_{p e t x i}-\sigma_{x i}\right)} \\
& r_{i}=\left[\frac{\left(\left(b_{i} / \mu_{i} T_{i}\left(1-\sigma_{p e t x i}-\sigma_{x i}\right)\right)+\eta m_{i} d i_{i}-\eta x_{i} d_{i}^{*}\right)}{\left(\left(1-\alpha x_{i}\right) \varepsilon x_{i}+\varepsilon m_{i} \alpha m_{i}+\alpha x_{i}-\alpha m_{i}\right)}\right]
\end{aligned}
$$

By using the equation (15), we can find out $e$, the degree of misalignment in bilateral nominal terms; the partner countries' misalignments are given by the previous multinational model:

$$
r_{i}=e_{i}+p x_{i}^{*}-p_{i}
$$

Like in the multinational model, we suppose that $p_{i}=\frac{\left(P_{i}-P_{i}^{e}\right)}{P_{i}^{e}}=0$

$$
e_{i}=r_{i}-\sum_{j \neq i} \lambda_{i j}\left(p x_{j}-e_{j}\right)
$$


We can also compute the effective exchange rate misalignments based on consumer prices (PD):

$$
\begin{aligned}
& R C_{i}=\frac{E_{i} P D_{i}^{*}}{P D_{i}} \\
& r c_{i}=e_{i}+p d_{i}^{*}-p d_{i} \\
& p d_{i}^{*}=\sum_{j \neq i} v_{i j}\left(p d_{j}-e_{j}\right) \\
& p d_{i}=\mu_{i} p m_{i}+\left(1-\mu_{i}\right) p_{i} \\
& p m_{i}=\alpha m_{i}\left(e_{i}+p m_{i}^{*}\right)+\left(1-\alpha m_{i}\right) p_{i} \\
& p d_{i}=\alpha m_{i} \mu_{i}\left(e_{i}+p m_{i}^{*}\right) \\
& r c_{i}=\left(1-\alpha m_{i} \mu_{i}\right) r_{i}+p d_{i}^{*}-p x_{i}^{*} \\
& r c_{i}=\left(1-\alpha m_{i} \mu_{i}\right) r_{i}+\sum_{j \neq i} v_{i j}\left(p d_{j}-e_{j}\right)-\sum_{j \neq i} \lambda_{i j}\left(p x_{j}-e_{j}\right)
\end{aligned}
$$

$\left(p d_{j}, e_{j}, p x_{j}\right.$ obtained thanks to the multinational model) 
Appendix 3: Foreign Trade Elasticities

\begin{tabular}{|c|c|c|c|c|c|c|c|}
\hline Country & Source & $\varepsilon_{x}$ & $\varepsilon_{m}$ & $\alpha_{x}$ & $\alpha_{m}$ & $\eta_{x}$ & $\eta_{m}$ \\
\hline Japan & $\begin{array}{c}\text { MIMOSA } \\
\text { NIGEM } \\
\text { Wren-Lewis } \\
\text { OECD }\end{array}$ & $\begin{array}{l}\mathbf{1 . 2 6} \\
1.19 \\
1.36 \\
1.05\end{array}$ & $\begin{array}{l}\mathbf{1 . 4 7} \\
0.61 \\
1.16 \\
0.40\end{array}$ & $\begin{array}{l}\mathbf{0 . 1 9} \\
0.24 \\
0.16 \\
0.28\end{array}$ & $\begin{array}{l}\mathbf{0 . 5 6} \\
1.00 \\
0.78 \\
0.51\end{array}$ & $\begin{array}{l}\mathbf{1 . 0 1} \\
1.00 \\
0.91 \\
1.00\end{array}$ & $\begin{array}{l}\mathbf{1 . 5 0} \\
1.69 \\
1.20 \\
1.00\end{array}$ \\
\hline China & $\begin{array}{l}\text { Dées } \\
\text { Brillet } \\
\text { OECD }\end{array}$ & $\begin{array}{l}\mathbf{0 . 7 1} \\
0.66 \\
1.50\end{array}$ & $\begin{array}{l}\mathbf{1 . 0 2} \\
0.46 \\
0.50^{*}\end{array}$ & $\begin{array}{l}\mathbf{0 . 5 6} \\
0.85 \\
1.00\end{array}$ & $\begin{array}{l}\mathbf{0 . 6 6} \\
0.60 \\
1.00\end{array}$ & $\begin{array}{l}\mathbf{0 . 7 5} \\
1.00 \\
1.00\end{array}$ & $\begin{array}{l}\mathbf{1 . 0 4} \\
0.98 \\
1.57^{*}\end{array}$ \\
\hline U.S. & $\begin{array}{c}\text { MIMOSA } \\
\text { NIGEM } \\
\text { Wren-Lewis } \\
\text { OECD }\end{array}$ & $\begin{array}{l}\mathbf{0 . 9 1} \\
0.52 \\
0.96 \\
0.60\end{array}$ & $\begin{array}{l}\mathbf{1 . 4 4} \\
0.61 \\
1.35 \\
0.33\end{array}$ & $\begin{array}{l}\mathbf{0 . 0 9} \\
0.00 \\
0.19 \\
0.07\end{array}$ & $\begin{array}{l}\mathbf{0 . 5 0} \\
1.00 \\
0.55 \\
0.36\end{array}$ & $\begin{array}{l}\mathbf{1 . 0 4} \\
1.00 \\
1.12 \\
1.00\end{array}$ & $\begin{array}{l}\mathbf{1 . 5 6} \\
2.52 \\
2.00 \\
1.00\end{array}$ \\
\hline U.K. & $\begin{array}{c}\text { MIMOSA } \\
\text { Wren-Lewis } \\
\text { OECD }\end{array}$ & $\begin{array}{l}\mathbf{0 . 7 0} \\
1.26 \\
0.60\end{array}$ & $\begin{array}{l}\mathbf{1 . 3 3} \\
0.22 \\
0.28\end{array}$ & $\begin{array}{l}\mathbf{0 . 0 7} \\
0.71 \\
0.47\end{array}$ & $\begin{array}{l}\mathbf{0 . 5 9} \\
0.75 \\
0.79\end{array}$ & $\begin{array}{l}\mathbf{0 . 8 7} \\
0.91 \\
1.00\end{array}$ & $\begin{array}{l}\mathbf{1 . 8 2} \\
2.00 \\
1.00\end{array}$ \\
\hline Euro area & $\begin{array}{c}E C B \\
\text { Hervé }\end{array}$ & $\begin{array}{l}0.50 \\
1.39\end{array}$ & $\begin{array}{l}0.81 \\
\mathbf{0 . 3 0}\end{array}$ & $\begin{array}{l}0.50 \\
\mathbf{0 . 7 5}\end{array}$ & $\begin{array}{l}0.51 \\
0.64\end{array}$ & $\begin{array}{l}1.00 \\
1.05\end{array}$ & $\begin{array}{l}0.51^{* *} \\
\mathbf{1 . 0 6}\end{array}$ \\
\hline RoW & $\begin{array}{c}\text { Ad hoc } \\
\text { Our estimates }\end{array}$ & $\begin{array}{l}\mathbf{1 . 0 0} \\
0.58\end{array}$ & $\begin{array}{l}1.00 \\
1.66\end{array}$ & $\begin{array}{l}\mathbf{0 . 5 0} \\
0.65\end{array}$ & $\begin{array}{l}\mathbf{1 . 0 0} \\
1.02\end{array}$ & $\begin{array}{l}1.00 \\
1.00\end{array}$ & $\begin{array}{l}\mathbf{1 . 0 0} \\
1.35\end{array}$ \\
\hline
\end{tabular}

(*Kwack et alii (2007), ** Non-oil import in volume) 
Appendix 4: Trade elasticities for European countries

\begin{tabular}{|c|c|c|c|c|c|c|c|}
\hline Country & Source & $\varepsilon_{x}$ & $\varepsilon_{m}$ & $\alpha_{x}$ & $\alpha_{m}$ & $\eta_{x}$ & $\eta_{m}$ \\
\hline France & $\begin{array}{c}\text { MIMOSA } \\
\text { NIGEM } \\
\text { OECD }\end{array}$ & $\begin{array}{l}\mathbf{0 . 6 6} \\
0.63 \\
0.60\end{array}$ & $\begin{array}{l}\mathbf{0 . 6 3} \\
0.59 \\
0.28\end{array}$ & $\begin{array}{c}\mathbf{0 . 4 1} \\
- \\
0.28\end{array}$ & $\begin{array}{c}\mathbf{0 . 6 3} \\
- \\
0.51\end{array}$ & $\begin{array}{l}\mathbf{0 . 8 8} \\
1.00 \\
1.00\end{array}$ & $\begin{array}{l}\mathbf{1 . 0 7} \\
1.51 \\
1.00\end{array}$ \\
\hline Germany & $\begin{array}{c}\text { MIMOSA } \\
\text { NIGEM } \\
\text { OECD }\end{array}$ & $\begin{array}{l}\mathbf{0 . 9 4} \\
0.55 \\
0.47\end{array}$ & $\begin{array}{l}\mathbf{0 . 8 2} \\
0.28 \\
0.30\end{array}$ & $\begin{array}{c}\mathbf{0 . 1 4} \\
- \\
0.18\end{array}$ & $\begin{array}{c}\mathbf{0 . 5 5} \\
- \\
0.64\end{array}$ & $\begin{array}{l}\mathbf{0 . 9 9} \\
1.00 \\
1.00\end{array}$ & $\begin{array}{l}\mathbf{0 . 8 6} \\
1.84 \\
1.00\end{array}$ \\
\hline Italy & $\begin{array}{c}\text { MIMOSA } \\
\text { NIGEM } \\
\text { OECD }\end{array}$ & $\begin{array}{l}\mathbf{1 . 2 6} \\
0.49 \\
0.60\end{array}$ & $\begin{array}{l}\mathbf{1 . 5 3} \\
0.73 \\
0.37\end{array}$ & $\begin{array}{c}\mathbf{0 . 5 7} \\
- \\
0.41\end{array}$ & $\begin{array}{c}\mathbf{0 . 6 5} \\
- \\
0.55\end{array}$ & $\begin{array}{l}\mathbf{0 . 8 7} \\
1.00 \\
1.00\end{array}$ & $\begin{array}{l}\mathbf{1 . 4 2} \\
1.50 \\
1.00\end{array}$ \\
\hline Spain & $\begin{array}{c}\text { Hervé } \\
\text { NIGEM } \\
\text { Saglio* }^{*} \\
\text { Aglietta** }^{*} \\
\text { OECD }\end{array}$ & $\begin{array}{c}1.11 \\
0.31 \\
\mathbf{1 . 5 0} \\
- \\
1.05\end{array}$ & $\begin{array}{c}0.45 \\
0.82 \\
\mathbf{0 . 8 0} \\
- \\
0.60\end{array}$ & $\begin{array}{c}- \\
- \\
- \\
\mathbf{0 . 5 2} \\
0.28\end{array}$ & $\begin{array}{c}- \\
- \\
- \\
\mathbf{0 . 8 0} \\
0.82\end{array}$ & $\begin{array}{c}\mathbf{1 . 0 0} \\
1.00 \\
- \\
- \\
1.00\end{array}$ & $\begin{array}{c}\mathbf{2 . 1 4} \\
1.00 \\
- \\
- \\
1.00\end{array}$ \\
\hline Austria & $\begin{array}{c}\text { NIGEM } \\
\text { Saglio* } \\
\text { Ad hoc } \\
\text { OECD }\end{array}$ & $\begin{array}{c}1.25 \\
\mathbf{0 . 8 0} \\
- \\
0.60\end{array}$ & $\begin{array}{c}0.31 \\
\mathbf{0 . 8 0} \\
- \\
0.16\end{array}$ & $\begin{array}{c}- \\
- \\
0.40 \\
0.18\end{array}$ & $\begin{array}{c}- \\
- \\
0.60 \\
0.51\end{array}$ & $\begin{array}{c}1.00 \\
- \\
- \\
1.00\end{array}$ & $\begin{array}{c}\mathbf{1 . 5 6} \\
- \\
- \\
1.00\end{array}$ \\
\hline Finland & $\begin{array}{l}\text { NIGEM } \\
\text { Saglio* } \\
\text { Ad hoc } \\
\text { OECD }\end{array}$ & $\begin{array}{c}1.20 \\
\mathbf{0 . 8 0} \\
- \\
0.60\end{array}$ & $\begin{array}{c}0.36 \\
\mathbf{1 . 0 0} \\
- \\
0.31\end{array}$ & $\begin{array}{c}- \\
- \\
0.40 \\
0.57\end{array}$ & $\begin{array}{c}- \\
- \\
\mathbf{0 . 6 0} \\
0.79\end{array}$ & $\begin{array}{c}1.00 \\
- \\
- \\
1.00\end{array}$ & $\begin{array}{c}1.17 \\
- \\
- \\
1.00\end{array}$ \\
\hline Ireland & $\begin{array}{l}\text { NIGEM } \\
\text { Saglio* } \\
\text { Ad hoc } \\
\text { OECD }\end{array}$ & $\begin{array}{c}4.28 \\
\mathbf{2 . 3 0} \\
- \\
0.60\end{array}$ & $\begin{array}{c}0.12 \\
\mathbf{0 . 8 0} \\
- \\
0.32\end{array}$ & $\begin{array}{c}- \\
- \\
\mathbf{0 . 4 0} \\
0.28\end{array}$ & $\begin{array}{c}- \\
- \\
0.60 \\
0.51\end{array}$ & $\begin{array}{c}1.00 \\
- \\
- \\
1.00\end{array}$ & $\begin{array}{c}\mathbf{1 . 0 8} \\
- \\
- \\
1.00\end{array}$ \\
\hline Netherlands & $\begin{array}{c}\text { NIGEM } \\
\text { Saglio* } \\
\text { Ad hoc } \\
\text { OECD }\end{array}$ & $\begin{array}{c}0.40 \\
\mathbf{1 . 8 8} \\
- \\
0.60\end{array}$ & $\begin{array}{c}0.37 \\
\mathbf{0 . 7 6} \\
- \\
0.28\end{array}$ & $\begin{array}{c}- \\
- \\
0.40 \\
0.41\end{array}$ & $\begin{array}{c}- \\
- \\
\mathbf{0 . 6 0} \\
0.36\end{array}$ & $\begin{array}{c}1.00 \\
- \\
- \\
1.00\end{array}$ & $\begin{array}{c}\mathbf{1 . 7 5} \\
- \\
- \\
1.00\end{array}$ \\
\hline Portugal & $\begin{array}{c}\text { NIGEM } \\
\text { Saglio* } \\
\text { Ad hoc } \\
\text { OECD }\end{array}$ & $\begin{array}{c}2.43 \\
\mathbf{1 . 1 0} \\
- \\
0.47\end{array}$ & $\begin{array}{c}0.25 \\
\mathbf{0 . 8 0} \\
- \\
0.56\end{array}$ & $\begin{array}{c}- \\
- \\
0.60 \\
0.77\end{array}$ & $\begin{array}{c}- \\
- \\
\mathbf{0 . 8 0} \\
0.79\end{array}$ & $\begin{array}{c}1.00 \\
- \\
- \\
1.00\end{array}$ & $\begin{array}{c}1.85 \\
- \\
- \\
1.00\end{array}$ \\
\hline
\end{tabular}

(*Mazier and Saglio, 2008, **Couharde and Mazier, 2000)

For European countries, the selected elasticities are those of the MIMOSA model for France, Germany and Italy. For the others European countries, we used the elasticities in bold. 


\section{Appendix 5: Sources}

\begin{tabular}{c|c}
\hline Variable & Source \\
\hline $\boldsymbol{C A S}$ & World Economic Outlook, IMF, April 2009 \\
\hline $\boldsymbol{I S N F A}$ & P.R. Lane and G.M. Milesi-Ferretti's Database, 2007 \\
\hline $\boldsymbol{C D R}, \boldsymbol{O D R}$ & World population prospect, ONU, Last update, September 28, 2007 \\
\hline $\boldsymbol{O}$ OG & Economic Outlook, OECD, December 2008 \\
\hline
\end{tabular}

\section{Appendix 6: Panel unit root test}

\begin{tabular}{c|c|c|c|c|c}
\hline Variables & CAS & ISNFA & CDR & ODR & OG \\
\hline Developed countries group & $-2.16^{* *}$ & $-1.20 * * *$ & $-3.83 * * *$ & $-11.29 * * *$ & $-7.65 * * *$ \\
\hline Emerging countries group & $-3.44 * * *$ & $-9.49 * * *$ & $-2.25 * *$ & $-8.76^{* * *}$ & $-14.32^{* * *}$ \\
\hline
\end{tabular}

(Source: authors' calculation)

$(* * *=$ Significant at $1 \%, * *=$ significant at $5 \%$ using the test statistic Im Pesaran Shin; the rejection of the null hypothesis (of the presence of unit root), leads us to reject non-stationarity of the series.) 


\section{Appendix 7: Current account targets for the others countries}
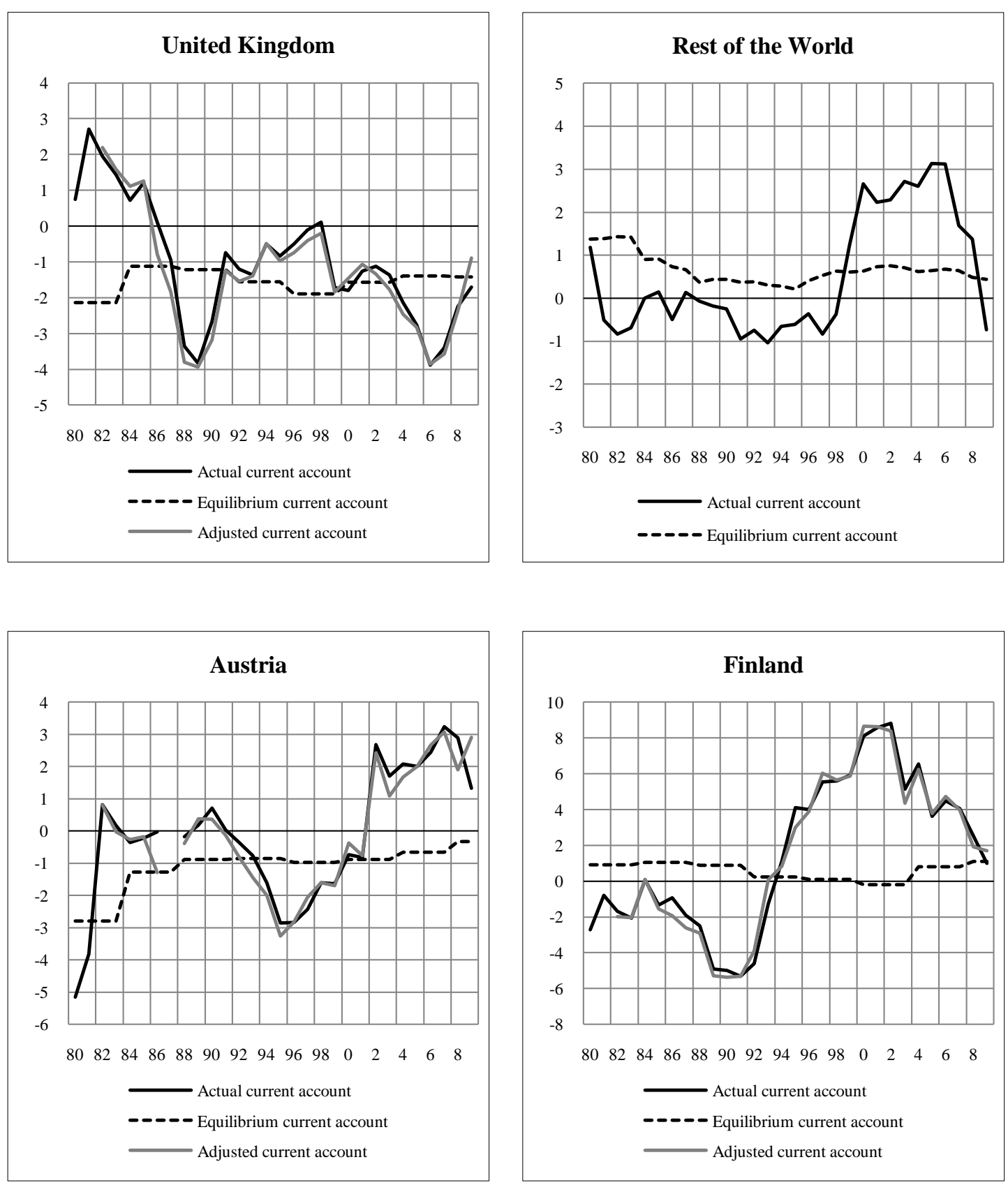


\section{Appendix 7: Current account targets for the others countries (cont'd)}
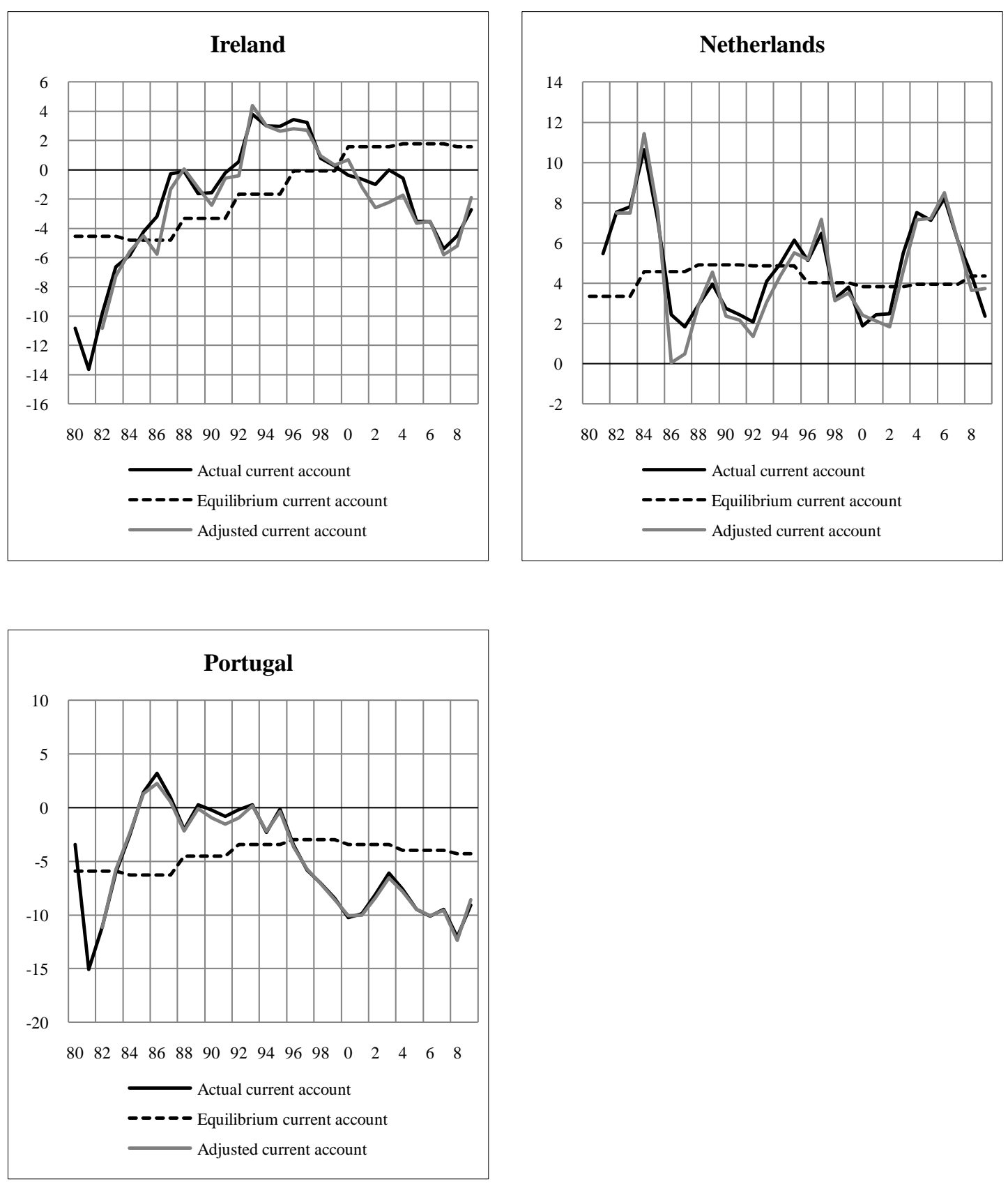

(Source: authors' calculations; IMF's World Economic Outlook, April 2009) 


\section{Appendix 8: Dynamic effects}

According to the multinational model for a country $\mathrm{i}$ :

$x_{i}=\eta x_{i} \sum_{j \neq i} \alpha_{i j} m_{j}+\varepsilon x_{i}\left(p m x_{i}-p x_{i}\right)$

But in reality, the effects of improved price competitiveness of exports on export volumes do not occur on a single period, there are delayed effects.

If we considered that:

$\operatorname{compx}_{i t}=\left(\operatorname{pmx}_{i t}-p x_{i t}\right)=d \log \left(C O M P X_{i t}\right)=d C O M P X_{i t} / C O M P X_{i t}$

$\operatorname{compx}_{i t}=\frac{\left(\mathrm{COMPX}_{i t}-\mathrm{COMPX} X_{i t}^{e}\right)}{C O M P X_{i t}^{e}}$

Then $^{8}$ :

$\varepsilon x_{i}\left(\operatorname{compx}_{i t}\right)=\varepsilon x_{i}^{1}\left(\operatorname{compx}_{i t}\right)+\varepsilon x_{i}^{2}\left(\operatorname{compx}_{i t-1}\right)+\varepsilon x_{i}^{3}\left(\operatorname{compx}_{i t-2}\right)$

If we considered that the follow equation describes the formation of the current account:

$B_{i}=P X_{i} X_{i}-P M_{i} M_{i}$

$b_{i}=\frac{B_{i}}{P_{i} Y_{i}}-\frac{B_{i}^{e}}{P_{i}^{e} Y_{i}^{e}}=d\left(\frac{B_{i}}{P_{i} Y_{i}}\right)=\mu_{i} d\left(\frac{B_{i}}{P M_{i} M_{i}}\right)=\mu_{i} d\left(\frac{P X_{i} X_{i}}{P M_{i} M_{i}}-\frac{P M_{i} M_{i}}{P M_{i} M_{i}}\right)=\mu_{i} d \tau_{i}$

$b_{i}=\mu_{i} \tau_{i} \frac{d \tau_{i}}{\tau_{i}}=\mu_{i} \tau_{i}\left[\frac{d P X_{i}}{P X_{i}}+\frac{d X_{i}}{X_{i}}-\frac{d P M_{i}}{P M_{i}}-\frac{d M_{i}}{M_{i}}\right]$

To compute the misalignment, we must take into account the future effects of changes in real effective exchange rates that have not yet produced. In the case of an improvement of price

${ }^{8} \varepsilon x_{i}=\varepsilon x_{i}^{1}+\varepsilon x_{i}^{2}+\varepsilon x_{i}^{3}$ 
competitiveness of exports (an increase of $\operatorname{compx}_{i t}$ : a real depreciation), the actual current account is lower than the adjusted current account.

In others words, the current account underestimates the future effects of this real depreciation. If we considered the current account in $\mathrm{t}$, the future effects of compx $x_{i t}$ will play in $\mathrm{t}+1$ and $\mathrm{t}+2$ $\left[\left(\varepsilon x_{i}^{2}\right) \operatorname{compx}_{i t}+\left(\varepsilon x_{i}^{3}\right) \operatorname{compx}_{i t}\right]$ and the effects of $\operatorname{compx}_{i t-1}$ will play in $\mathrm{t}+1\left[\left(\varepsilon x_{i}^{3}\right) \operatorname{compx}_{i t-1}\right]$.

We obtain:

$$
\begin{aligned}
& \frac{d X_{i}}{X_{i}}=\left(\varepsilon x_{i}^{2}+\varepsilon x_{i}^{3}\right)\left(1-\alpha x_{i}\right) r x_{i t}+\left(\varepsilon x_{i}^{3}\right)\left(1-\alpha x_{i}\right) r x_{i t-1} \\
& \frac{d M_{i}}{M_{i}}=\left(\varepsilon m_{i}^{2}+\varepsilon m_{i}^{3}\right)\left(\alpha m_{i}\right) r m_{i t}+\left(\varepsilon m_{i}^{3}\right)\left(\alpha m_{i}\right) r m_{i t-1}
\end{aligned}
$$

With $r x_{i t}=\left(p m x_{i t}-p_{i t}\right)$ and $r m_{i t}=\left(p d_{i t}-p m m_{i t}\right)$

Using the equations (21), (22) and (23), we write the formula of dynamic effects:

$$
b_{i}^{c}=\mu_{i} \tau_{i}\left[\left(\varepsilon x_{i}^{2}+\varepsilon x_{i}^{3}\right)\left(1-\alpha x_{i}\right) r x_{i t}+\left(\varepsilon x_{i}^{3}\right)\left(1-\alpha x_{i}\right) r x_{i t-1}-\left(\varepsilon m_{i}^{2}+\varepsilon m_{i}^{3}\right)\left(\alpha m_{i}\right) r m_{i t}-\left(\varepsilon m_{i}^{3}\right)\left(\alpha m_{i}\right) r m_{i t-1}\right]
$$

To correct the current account from the dynamic effects, we calculate:

$$
b_{i}^{\text {adjusted }}=b_{i}^{\text {actual }}+b_{i}^{c}
$$

For the national model, the formula is slightly different:

$$
\begin{aligned}
& \frac{d X_{i}}{X_{i}}=\left(\varepsilon x_{i}^{2}+\varepsilon x_{i}^{3}\right)\left(1-\alpha x_{i}\right) r_{i t}+\left(\varepsilon x_{i}^{3}\right)\left(1-\alpha x_{i}\right) r_{i t-1} \\
& \frac{d M_{i}}{M_{i}}=-\left(\varepsilon m_{i}^{2}+\varepsilon m_{i}^{3}\right)\left(\alpha m_{i}\right) r_{i t}-\left(\varepsilon m_{i}^{3}\right)\left(\alpha m_{i}\right) r_{i t-1}
\end{aligned}
$$

Using the equations (21), (22.a) and (23.a), we write the formula of dynamic effects for the national model:

$$
b_{i}^{c}=\mu_{i} \tau_{i}\left[\left(\varepsilon x_{i}^{2}+\varepsilon x_{i}^{3}\right)\left(1-\alpha x_{i}\right) r_{i t}+\left(\varepsilon x_{i}^{3}\right)\left(1-\alpha x_{i}\right) r_{i t-1}+\left(\varepsilon m_{i}^{2}+\varepsilon m_{i}^{3}\right)\left(\alpha m_{i}\right) r_{i t}+\left(\varepsilon m_{i}^{3}\right)\left(\alpha m_{i}\right) r_{i t-1}\right]
$$

With $r_{i t}=d \log \left(R_{i t}\right)$, the growth rate of the real effective exchange rate. 
Under the Microsoft Excel software,

$$
\begin{aligned}
& r x_{t}=d \log \left[\frac{P M X}{P}\right]_{t} * 100=\left[\log \left[\frac{P M X}{P}\right]_{t}-\log \left[\frac{P M X}{P}\right]_{t-1}\right]^{* 100} \\
& r m_{t}=d \log \left[\frac{P D}{P M M}\right]_{t} * 100=\left[\log \left[\frac{P D}{P M M}\right]_{t}-\log \left[\frac{P D}{P M M}\right]_{t-1}\right] * 100 \\
& r_{t}=d \log R_{t} * 100=\left[\log R_{t}-\log _{t-1}\right] * 100
\end{aligned}
$$

The elasticities $\varepsilon x_{i}^{1}, \varepsilon x_{i}^{2}, \varepsilon x_{i}^{3}$ are obtained by the estimation of an Error Correcting Model of the world trade (like NIGEM for instance). The price series (PMX, PMM, $P$ and $P D)$ are actual data extracted from databases such as those of the OECD or those of the IMF. 


\section{Appendix 9: Ex post targets}

In order to calculate the ex post targets, we reverse the six models. The ex post models have the FEERs as exogenous variables and produce the targets which are reached by these FEERs as endogenous variables. Like in the case of the misalignments, we made an OCI average to calculate the ex post average targets.

The ex post targets $b_{i}$ reached by the FEERs are given by the equation:

$b_{i}=\mu_{i} T_{i}\left(1-\sigma_{p e t x i}-\sigma_{x i}\right)\left(p x_{i}+x_{i}-p m_{i}-m_{i}\right)$

Where $p x_{i}, p m_{i}, x_{i}$ and $m_{i}$ depend of the bilateral misalignments $e_{i}$ which have been calculated (equations 1', 2', 5' and 6'). For $x_{i}$, we have as an example:

$x_{i}=\eta x_{i} \sum_{j \neq i} \alpha_{i j} m_{j}+\left[\varepsilon x_{i}\right]\left[\sum_{j \neq i} \lambda_{i j}\left(p x_{j}-e_{j}\right)\right]+\left[\varepsilon x_{i}\right] e_{i}-\left[\varepsilon x_{i}\right] p x_{i}$

Ex post average targets are calculated using the OCI method. Table 7 gives the difference between ex ante and ex post targets. The average deviation is inferior to $0.3 \%$ of GDP for the period 2004-2009 (in absolute value). Each year, the relative average must be close to zero because the sum of the targets in dollars is equal to zero at the world level. In a given period, if a country undergoes an over-adjustment, the trading partners should operate a less pronounced adjustment to ensure the global consistency.

Table 7: Difference between ex ante and ex post targets

\begin{tabular}{cccccccc}
\hline & $\boldsymbol{C H N}$ & $\boldsymbol{E U}$ & $\boldsymbol{J P N}$ & $\boldsymbol{U K}$ & $\boldsymbol{U S}$ & RoW & Average \\
\hline $\mathbf{2 0 0 4}$ & 0.08 & -0.34 & -0.38 & -1.29 & 0.65 & -0.20 & $\mathbf{- 0 . 2 5}$ \\
$\mathbf{2 0 0 5}$ & -0.50 & -0.50 & -0.19 & -0.35 & 0.36 & -0.43 & $\mathbf{- 0 . 2 7}$ \\
$\mathbf{2 0 0 6}$ & -0.81 & -0.56 & 0.17 & 0.55 & 0.34 & -0.39 & $\mathbf{- 0 . 1 2}$ \\
$\mathbf{2 0 0 7}$ & -1.08 & -0.36 & 0.16 & 0.76 & 0.74 & -0.01 & $\mathbf{0 . 0 4}$ \\
$\mathbf{2 0 0 8}$ & -1.21 & -0.22 & -0.53 & 0.19 & 0.75 & 0.35 & $\mathbf{- 0 . 1 1}$ \\
$\mathbf{2 0 0 9}$ & -0.56 & 0.81 & -0.95 & -0.23 & 0.05 & 2.29 & $\mathbf{0 . 2 3}$ \\
\hline Average & $\mathbf{- 0 . 6 8}$ & $\mathbf{- 0 . 1 9}$ & $\mathbf{- 0 . 2 9}$ & $\mathbf{- 0 . 0 6}$ & $\mathbf{0 . 4 8}$ & $\mathbf{0 . 2 7}$ & $\mathbf{- 0 . 0 8}$ \\
\hline (Source: author's calculations) & & & & &
\end{tabular}




\section{Appendix 10: Sensitivity tests}

Considering the existing uncertainties in the estimation of external and internal equilibrium and in the measure of trade elasticities, three kinds of sensibility tests have been performed:

- an increase of the target current balance of $1 \%$ of GDP $(b c)$;

- an increase of the potential production of $1 \%\left(y^{e}\right)$;

- an increase of the export price elasticity of $20 \%\left(\varepsilon_{x}\right)$;

- an increase of the import price elasticity of $20 \%\left(\varepsilon_{m}\right)$.

Table 8: Sensitivity tests on real effective exchange rates $(r c)$ (Absolute average of changes from the base simulation results)

\begin{tabular}{ccccc}
\hline & $\boldsymbol{b} \boldsymbol{c}$ & $\boldsymbol{y}^{\boldsymbol{e}}$ & $\boldsymbol{\varepsilon}_{\boldsymbol{x}}$ & $\boldsymbol{\varepsilon}_{\boldsymbol{m}}$ \\
\hline $\boldsymbol{F R \boldsymbol { A }}$ & 0.0242 & 0.0049 & 0.0047 & 0.0048 \\
$\boldsymbol{G E R}$ & 0.0116 & 0.0026 & 0.0051 & 0.0031 \\
$\boldsymbol{I T A}$ & 0.0101 & 0.0025 & 0.0011 & 0.0020 \\
$\boldsymbol{S P A}$ & 0.0176 & 0.0051 & 0.0101 & 0.0091 \\
$\boldsymbol{A} \boldsymbol{U} \boldsymbol{T}$ & 0.0107 & 0.0011 & 0.0022 & 0.0022 \\
$\boldsymbol{F I N}$ & 0.0100 & 0.0034 & 0.0061 & 0.0074 \\
$\boldsymbol{I R L}$ & 0.0038 & 0.0017 & 0.0021 & 0.0008 \\
$\boldsymbol{N L D}$ & 0.0044 & 0.0033 & 0.0014 & 0.0006 \\
$\boldsymbol{P R T}$ & 0.0184 & 0.0054 & 0.0079 & 0.0110 \\
\hline
\end{tabular}

(Source: authors' calculation)

Several informations can be withdrawn from these results (Table 8):

- $\quad$ The sensitivity to the potential production is limited. A higher potential production and consequently an increased under-utilisation of production capacities lead to a more significant real overvaluation of the currency. The elasticity is between -0.1 and -0.5 meaning that an additional under-utilisation of $1 \%$ results in an increased overvaluation between $-0.1 \%$ and $0.5 \%$.

- The sensitivity to the current account target is moderate. An increase in the current account target that is a reduction of the gap $b$ leads to an overvaluation of the concerned currency. The effect weakens as the GDP share of exports and the elasticity of current account to real exchange rate increase. 
- $\quad$ The sensitivity to the export and import price elasticities also turns out to be small. On the whole higher export price elasticity leads to smaller changes in exchange rates to absorb the same amount of current account imbalances. Absolute average of results means the degree of lesser misalignments of exchange rates under higher price elasticity. This result is reassuring considering the existing uncertainties in the estimation of these parameters.

These sensitivity tests assure that the FEER approach provides rather robust results in spite of uncertainties in estimating the internal and external equilibrium and the parameters of trade equations. 


\section{Appendix 11: Intra-european misalignments}

The weighted sum (by the GDP) of the intra-european misalignments is equal to the euro misalignments. Our estimates of intra-european misalignments are derived from the national model. The weighted sum of these misalignments is very near from the euro misalignments itself. When there was a discrepancy, we have distributed the difference (between the misalignments of the euro and the weighted sum of intra-european misalignments) proportionately to the weight of the country in the euro area GDP. The average correction is very modest ( 3.6 percent on the whole period).

Table 9: Coherence between national and euro misalignments

\begin{tabular}{l|c|c|c}
\hline & $\sum_{i=1}^{9} r c_{i}^{*} \frac{G D P_{i}}{\left(\sum_{i=1}^{9} G D P_{i}\right)}$ & reu & Difference \\
\hline $\mathbf{1 9 9 4}$ & -2.7 & & \\
$\mathbf{1 9 9 5}$ & -1.5 & -3.4 & 0.7 \\
$\mathbf{1 9 9 6}$ & 0.2 & 1.2 & -2.7 \\
$\mathbf{1 9 9 7}$ & 3.1 & 4.2 & -4.0 \\
$\mathbf{1 9 9 8}$ & 1.1 & 3.5 & -0.4 \\
$\mathbf{1 9 9 9}$ & 0.3 & 0.6 & 0.4 \\
$\mathbf{2 0 0 0}$ & -2.3 & 2.0 & -1.7 \\
$\mathbf{2 0 0 1}$ & -2.5 & 0.1 & -2.4 \\
$\mathbf{2 0 0 2}$ & -2.2 & 6.8 & -9.3 \\
$\mathbf{2 0 0 3}$ & -4.6 & 6.6 & -8.8 \\
$\mathbf{2 0 0 4}$ & -3.5 & 2.2 & -6.8 \\
$\mathbf{2 0 0 5}$ & -4.8 & 6.0 & -9.4 \\
$\mathbf{2 0 0 6}$ & -4.0 & -0.4 & -4.4 \\
$\mathbf{2 0 0 7}$ & -4.7 & -1.7 & -2.4 \\
$\mathbf{2 0 0 8}$ & -9.3 & -4.1 & -0.6 \\
$\mathbf{2 0 0 9}$ & -3.2 & -4.9 & -4.4 \\
\hline
\end{tabular}

rci*: national misalignments before correction

(Source: author's calculations) 
Appendix 12: Equilibrium effective exchange rates of european countries $(2000=$ 100)
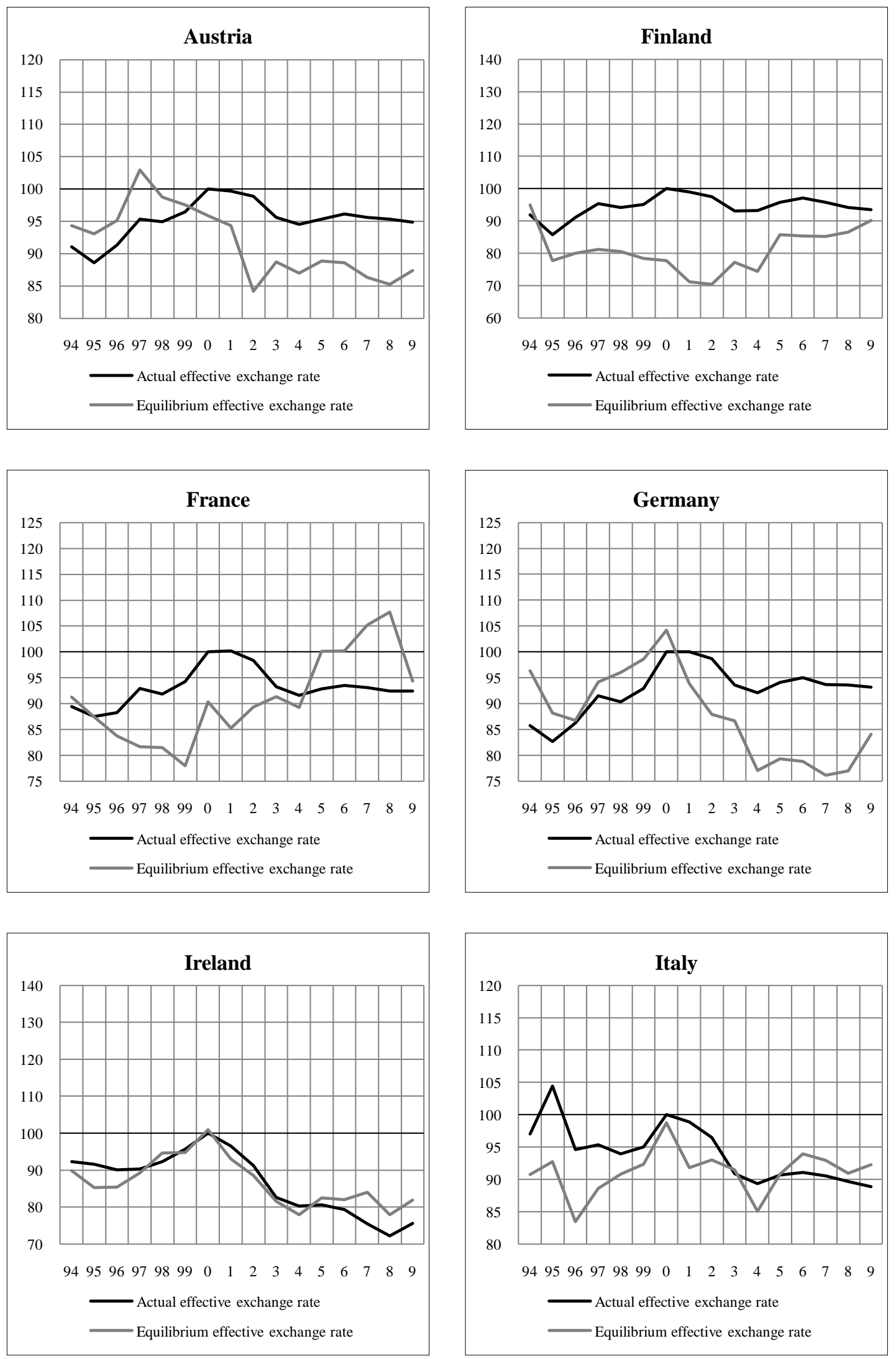
Appendix 12: Equilibrium effective exchange rates of european countries $(2000=$ 100) (cont'd)
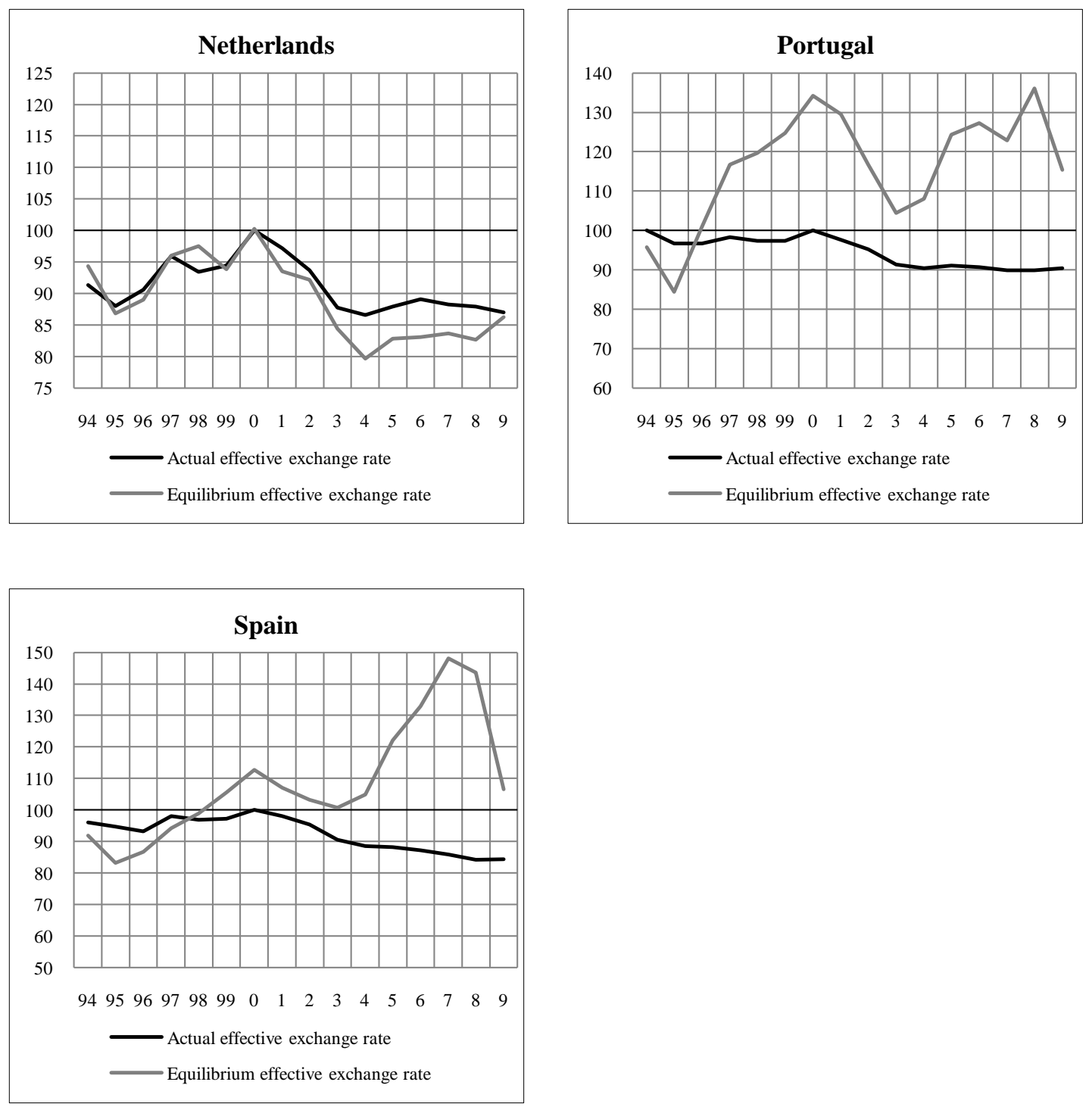

(Source: authors' calculations, Bank for International Settlements for the real effective exchange rate (annual average of monthly data)) 
Appendix 13: Misalignments for each 'national euro' $(2000=100)$
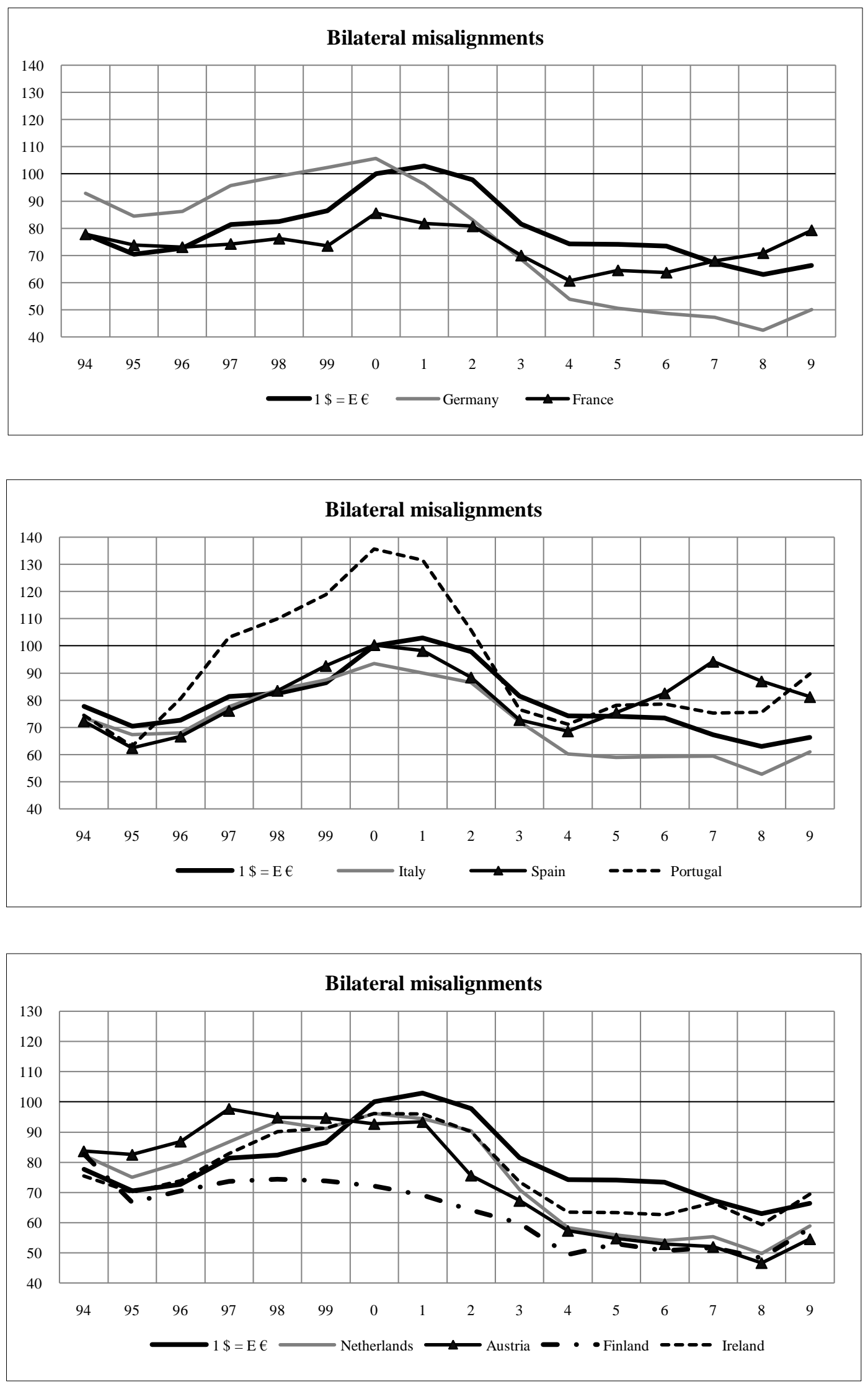

(Source: authors' calculations, OECD for bilateral exchange rates) 